RECEIVED BY TIC NOV 181976

PARAMETER STUDIES ON

THE EFFECT OF PULSE SHAPE ON THE

DYNAMIC PLASTIC DEFORMATION OF A HEXAGON

Carl K. YoungdahI

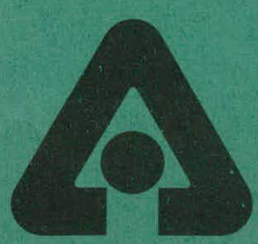

ARGONNE NATIONAL LABORATORY, ARGONNE, ILLINOIS

Prepared for the U.S. ATOMIC ENERGY COMMISSION

Division of Reactor Research and Development under Contract W-31-109-Eng-38 


\section{DISCLAIMER}

This report was prepared as an account of work sponsored by an agency of the United States Government. Neither the United States Government nor any agency Thereof, nor any of their employees, makes any warranty, express or implied, or assumes any legal liability or responsibility for the accuracy, completeness, or usefulness of any information, apparatus, product, or process disclosed, or represents that its use would not infringe privately owned rights. Reference herein to any specific commercial product, process, or service by trade name, trademark, manufacturer, or otherwise does not necessarily constitute or imply its endorsement, recommendation, or favoring by the United States Government or any agency thereof. The views and opinions of authors expressed herein do not necessarily state or reflect those of the United States Government or any agency thereof. 


\section{DISCLAIMER}

Portions of this document may be illegible in electronic image products. Images are produced from the best available original document. 
The facilities of Argonne National Laboratory are owned by the United States Government. Under the terms of a contract (W-31-109-Eng-38) between the U. S. Atomic Energy Commission, Argonne Universities Association and The University of Chicago, the University employs the staff and operates the Laboratory in accordance with policies and programs formulated, approved and reviewed by the Association.

\section{MEMBERS OF ARGONNE UNIVERSITIES ASSOCIATION}

The University of Arizona

Carnegie-Mellon University

Case Western Reserve University

The University of Chicago

University of Cincinnati

Illinoig Institute of Technology

Universily of Illinoir.

Indlatid Uuiveroity

Iowa State University

The University of Iowa
Kansas State University

The University of Kansas

Loyola University

Marquette University

Michigan State University

The University of Michigan

University of Minuesuta

University of Missour

Northwestern University

University of Notre Dame
The Ohio State University

Ohio University

The Pennsylvania State University

Purdue University

Saint Louis University

Southern Illinois University

The IIniversity of Texas at Austin

Waslington University

Wayue State Univeraity

The University of Wisconsin

\section{NOTICE}

This report was prepared as an account of work sponsored by the United States Government. Neither the United States nnr the United States Atomic Energy Commission, nor any of their employees, nor any of their contracturs, sulcontrac tors, or their employees, makes diry warranly, sxprnan or implied, or assumes any legal liability or responsibility for the accuracy, completcness or usefulness of any information, apparatus, product or process disclosed, or represents that its use would not infringe privately-owned rights.

Printed in the United States of America Available from

National Technical Information Service

U.S. Department of Commerce 5285 Port Royal Road

Springfield, Virginia 22151

Price: Printed Copy $\$ 4.00 ;$ Microfiche $\$ 1.45$ 
ANL-8012

LMFBR Slructural Matcrials and" Design Engineering

(U.C-7.9h)

\section{ARGONNE NATIONAL LABBORATORY'}

9700 South Cass Avenue

Argonne, Illinois. 60439 :

PARAMETER STUDIES ON

THE EFFECT OF PULSE SHAPE ON THE

DYNAMIC PLASTIC DEFORMATION OF A HEXAGON

by

Carl K. Youngdahl

Components Technology Division

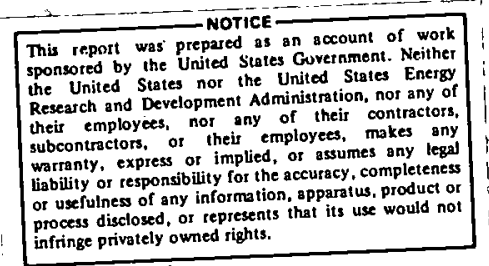

October 1973 


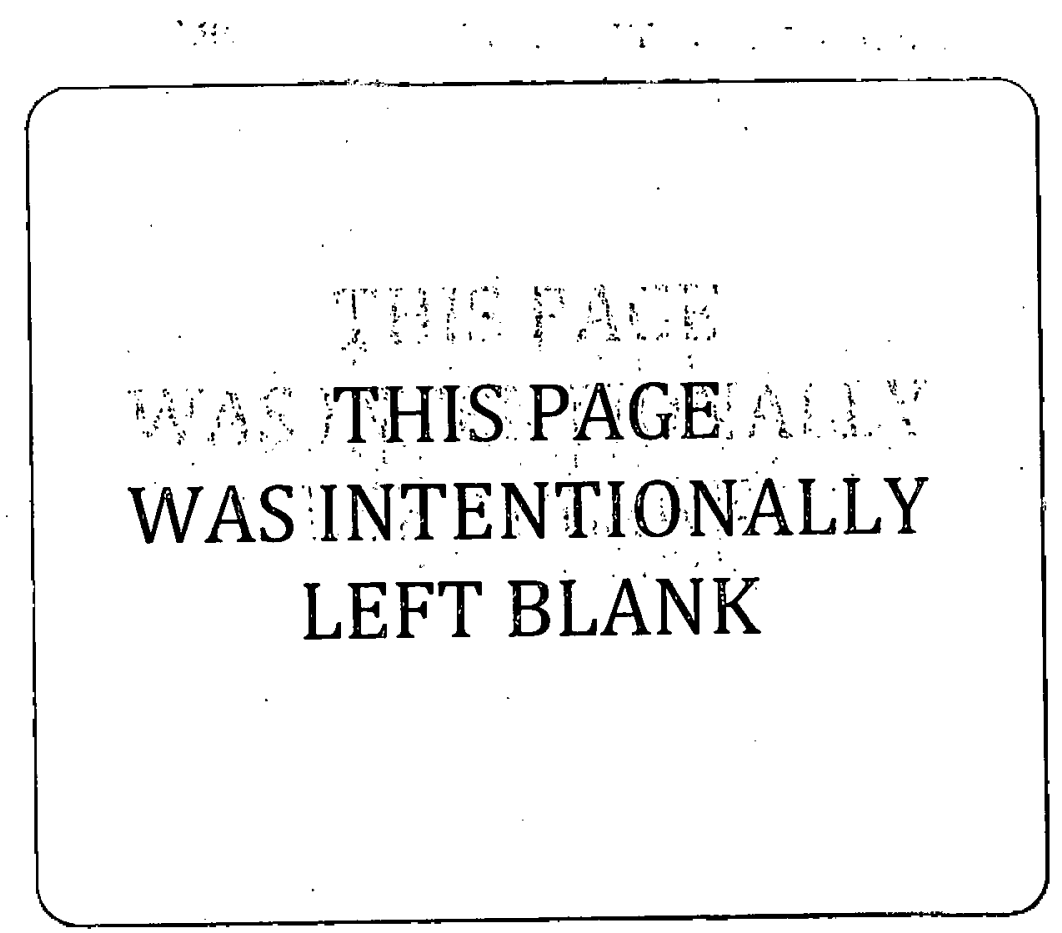


TABLE OF CONTENTS

$\underline{\text { Page }}$

ABSTRACT .......................... 7

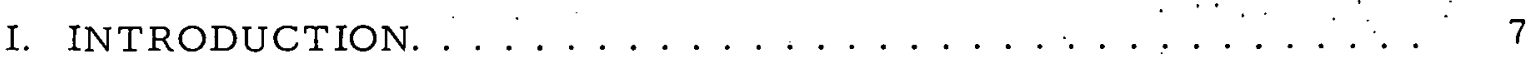

II. SUMMARY STATEMENT OF PROBLEM. . . . . . . . . . . . 9

III. CHARACTERISTICS OF RESPONSE TO RECTANGUULAR

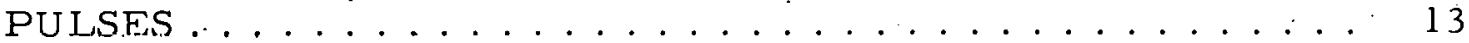

IV. RECTANGULAR-PULSE RESPONSE IN SMALL-DEFORMATION RANGE. $\cdots$

V. EFFECT OF PULSE SHAPE IN SMALL-DEFORMATION

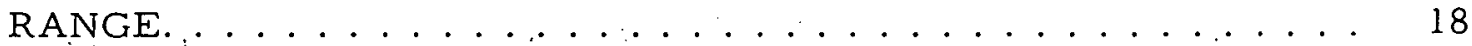

VI. LARGE-DEFORMATION RESPONSE TO STEP PULSES . . . . 23

VII. EFFECT OF PULSE SHAPE ON LARGE-DEFORMATION

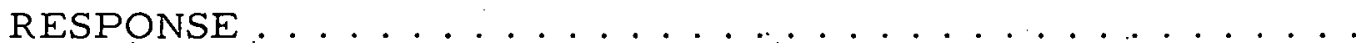

VIII. DYNAMIC LOAD FACTOR FOR PLASTIC DEFORMATION . . . . 29

IX. EXAMPLE PROBLEMS FOR BOUNDING PROCEDURE．... . 32

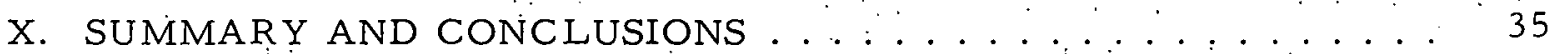

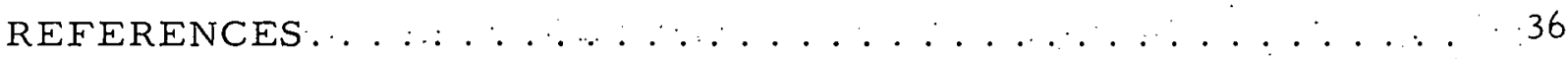




\section{- LIST. OF FIGURES}

No.

Title

Page

1. Hexagon Subjected to Internal Pressure Pulse . . . . . . . . . 9

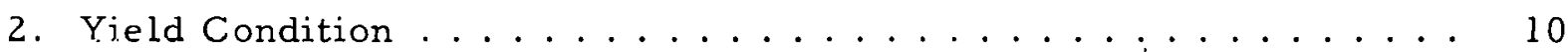

3. Limit Load of Undistorted Hexagon . . . . . . . . . . . . . 10

4. Time Constant $t_{0}$ as a Function of Yield Stress for Typical Hexagonal Subassembly Ducts................. 11

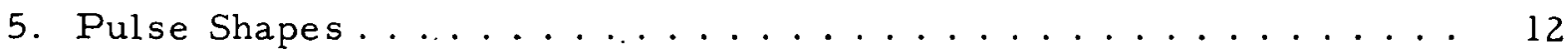

6. Midside Deflection as a Function of Time for Rectangular Pulses of Various Durations: $\alpha=0.03, \mathrm{P}_{\mathrm{r}}=2 \mathrm{P}_{\mathrm{y}}=0.00712 \sigma_{\mathrm{y}} \ldots \ldots$

7. Midside Deflection as a Function of Time for Rectangular Pulses of Various Durations: $\alpha=0.056, \mathrm{P}_{\mathrm{r}}=2 \mathrm{P}_{\mathrm{y}}=0.02421 \sigma_{\mathrm{y}} \ldots$

8. Corner Deflection as a Function of Time for Rectangular Pulses of Various Durations: $\alpha=0.03, \mathrm{P}_{\mathrm{r}}=2 \mathrm{P}_{\mathrm{y}}=0.00712 \sigma_{\mathrm{y}} \ldots \ldots$

9. Corner Deflection as a Function of Time for Rectangular Pulses of Various Durations: $\alpha=0.056, \mathrm{P}_{\mathrm{r}}=2 \mathrm{P}_{\mathrm{y}}=0.0242 \mathrm{l} \sigma_{\mathrm{y}} \ldots .$. .

10. Final Midside Deflection and Response Duration as Functions of Rectangular-pulse Durations: $\alpha=0.03, \mathrm{P}_{\mathrm{r}}=2 \mathrm{P}_{\mathrm{y}}=0.00712 \sigma_{\mathrm{y}}$.

11. Final Midside Deflection and Response Duration as Functions of Rectangular-pulse Durations: $\alpha=0.056, \mathrm{P}_{\mathrm{r}}=2 \mathrm{P}_{\mathrm{y}}=0.02421 \sigma_{\mathrm{y}}$.

12. Comparison of Exact and Approximate Solutions for Respnnse to Rectangular Pulse in Small-deformation Range: $\alpha=0.056 \ldots$. .

13. $\mathrm{U}_{\mathrm{Bf}} \mathrm{t}_{0}^{2} / \mathrm{Ht}_{\mathrm{r}}^{2}$ as a Function of $\mathrm{P}_{\mathrm{r}} / \sigma_{\mathrm{y}}$ in Small-deformation Range for Various $\alpha \ldots \ldots \ldots \ldots \ldots \ldots \ldots$

14. $\mathrm{U}_{\mathrm{Bf}} \mathrm{t}_{0}^{2} / \mathrm{Ht}_{\mathrm{r}}^{2}$ as a Function of $\mathrm{P}_{\mathrm{r}} / \mathrm{P}_{\mathrm{y}}$ in Small-deformation Range for

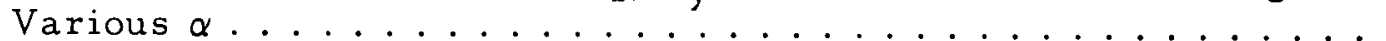

15. Ratio of Response Duration to Pulse Duration as a Function of $\mathrm{P}_{\mathrm{r}} / \mathrm{P}_{\mathrm{y}}$ in Small-deformation Range ................ 18

16. $\mathrm{P}_{\mathrm{y}} \mathrm{t}_{\mathrm{f}} / \mathrm{P}_{\mathrm{r}} \mathrm{t}_{\mathrm{r}}$ as a Function of $\mathrm{P}_{\mathrm{r}} / \mathrm{P}_{\mathrm{y}}$ in Small-deformation Range . . . 18

17. Pulse Parameters for Arbitrary Pulse............... 20

18. $\left(\mathrm{U}_{\mathrm{Bf}} / \mathrm{H}\right)\left(\mathrm{P}_{\mathrm{y}} \mathrm{t}_{0} / \mathrm{I}\right)^{2}$ as a Function of $\mathrm{P}_{\mathrm{m}} / \mathrm{P}_{\mathrm{y}}$ in Small-deformation Range for Several Pulse Shapes: $\alpha=0.03 \ldots \ldots . . . \ldots$

19. $\left(\mathrm{U}_{\mathrm{Bf}} / \mathrm{H}\right)\left(\mathrm{P}_{\mathrm{y}} \mathrm{t}_{0} / \mathrm{I}\right)^{2}$ as a Function of $\mathrm{P}_{\mathrm{e}} / \mathrm{P}_{\mathrm{y}}$ in Small-deformation Range for Several Pulse Shapes: $\alpha=0.03 \ldots \ldots$

20. $\left(\mathrm{U}_{\mathrm{Bf}} / \dot{\mathrm{H}}\right)\left(\mathrm{P}_{\mathrm{y}} \mathrm{t}_{0} / \mathrm{I}\right)^{2}$ as a Function of $\mathrm{P}_{\mathrm{m}} / \mathrm{P}_{\mathrm{y}}$ in Small-deformation Range for Several Pulse Shapes: $\alpha=0.056 \ldots \ldots$ 


\section{LIST OF.FIGURES}

No.

21. $\left(\mathrm{U}_{\mathrm{Bf}} / \mathrm{H}\right)\left(\mathrm{P}_{\mathrm{y}} \mathrm{t}_{\mathrm{o}} / \mathrm{I}\right)^{2}$ as a Function of $\mathrm{P}_{\mathrm{e}} / \mathrm{P}_{\mathrm{y}}$ in Small-deformation Range for Several Pulse Shapes: $\alpha=0.056 \ldots \ldots$

22. $t_{f} P_{y} / I$ as a Function of $P_{e} / P_{y}$ in. Small-deformation Range for Several Pulse Shapes: $\alpha=0.03 \ldots \ldots \ldots$

23. $t_{f} P_{y} / I$ as a Function of $P_{e} / P_{y}$ in Small-deformation Range for Several Pulse Shapes: $\alpha=0.056 \ldots \ldots \ldots$

24. Final Midside Deflection in Large-deformation Range as a Function of Step-pulse Height for Various $\alpha \ldots \ldots \ldots$

25. Final Midside Deflection in Large-deformation Range as a Function of $\alpha$ for Various Values of $\mathrm{P}_{\mathrm{m}} / \mathrm{P}_{\mathrm{y}} \ldots \ldots \ldots$

26. Final Corner Deflection in Large-deformation Range as a Function of Step-pulse Height for Various $\alpha \ldots \ldots \ldots$

27. Response Time in Large-deformation Range as a Function of Step-pulse Height for Various $\alpha \ldots \ldots \ldots$

28. Comparison of Results in Large-deformation Range for Exponential-decay and Step Pulses: $\alpha=0.056 \ldots \ldots$

29. Comparison of Results in Large-deformation Range for Lineardecay and Step Pulses: $\alpha=0.056 \ldots \ldots \ldots \ldots$

30. Comparis on of Results in Large-deformation Range for Exponential-decay and Step Pulses: $\alpha=0.03 \ldots \ldots \ldots$

31. Response Duration for Exponential-decay Pulse as a Function of Pulse Time Constant for Various Values of Peak Pressure:

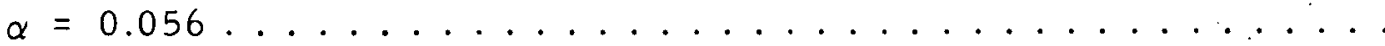

32. Response Duration for Linear-decay Pulse as a Function of Pulse Duration for Various Values of Peak Pressure: $\alpha=0.056$

33. Response Duration for Exponential-decay Pulse as a Function of Pulse Time Constant for Various Values of Peak Pressure:

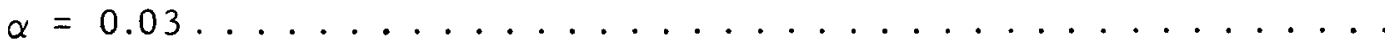

34. Applied Impulse during Deformation Produced by an Exponentialdecay Pulse: $\alpha=0.056 \ldots \ldots \ldots \ldots \ldots \ldots$

35. $t_{f} P_{y} / I$ in Large-deformation Range for an Exponential-decay Pulse: $\alpha=0.056 \ldots \ldots \ldots \ldots \ldots$

36. Angular Deflection of Half-side of Hexagon Produced by Static

37. Midside Deflection Produced by Static Load . . . . . . . . . . 


\section{LIST' OF FIGURES}

No.

Title

Page

38. Corner:Deflection Produced by Static Load . . . . . . . . . 31

39. Dynamic-load Factor as a Function of $\mathrm{P}_{\mathrm{m}} / \mathrm{P}_{\mathrm{y}}$ for Various $\alpha \ldots 31$

40. Comparison of Results and Bounds for Example Problems:

$$
\alpha=0.03, \mathrm{P}_{\mathrm{m}}=0.006 \sigma_{\mathrm{y}} \ldots \ldots \ldots \ldots \ldots
$$




\title{
PARAMETER STUDIES ON \\ THE EFFECT OF PULSE SHAPE ON THE \\ DYNAMIC PLASTIC DEFORMATION OF A HEXAGON
}

by

Carl K. Youngdahl

\begin{abstract}
This report presents resulls of a parameter study on the dynamic plastic response of a hexagonal subassembly duct subjected to an internal pressure pulse of arbitrary shape. Plastic distortion of the cross section and large-deformation geometric effects that result in redistribution of the internal forces between bending and membrane stresses in the hexagon wall are included in the analytical model. Correlation procedures are established for relating permanent plastic deformation to simple properties of the pressure pulse, for both the small-and large-deformation ranges. Characteristic response times are determined, and the dynamic load factor for largedeformation plastic response is computed.
\end{abstract}

\section{INTRODUCTION}

Fuel-pin failure in a reactor may produce a pressure pulse that acts on the next line of containment: the hexagonal subassembly duct. The response of the duct to an internal pressure pulse can be divided into four categories, depending on the peak pressure, the pulse shape, and the pulse duration:

1. The peak pressure is not high enough to produce plastic deformation of the duct. The response is then entirely elastic, and the duct returns to its original shape after the pulse ceases.

2. The peak pressure is higher than the plastic yield load of the duct, but the duration of the pulse is sufficiently short that only small permanent distortion of the duct occurs. "Small" distortion here means that the maximum change in dimension across flats of the hexagonal cross section is significantly less than the wall thickness of the duct. Some subassembly-removal problems may be encountered for distortions in this range. Also, cracking of the duct may occur at the corners or center-of-sides of the cross section, where the strains are highest, particularly if the duct material has been embrittled by radiation: 
3. The peak pressure exceeds the plastic yield load of the duct, the pulse shape and duration are such that the hexagonal cross section is distorted into an irregular 12 -sided figure, and the wall deformations are large. "Large" deformations are taken here to be those such that the change in dimension across flats of the duct is of the same order as or exceeds the wall thickness. The cross section distorts into a shape that has a higher limit load than the undeformed hexagon, so that the plastic-deformation response may cease while the applied pressure still exceeds the original limit load. Subassembly-removal difficulties will be encountered for deformations of this size because of the jamming of the duct into the adjacent circle of ducts.

4. The pressure pulse is such that gross distortion or failure of the duct occurs, and the cross section becomes an irregular figure of 24 or more sides, which may become nearly circular if the duct material is sufficiently ductile. Under this severe loading, it is likely that adjacent subassemblies also will be deformed and fuel element failures will propagate through a portion of the core.

Accordingly, an analytical study has been performed to determine the dynamic response of a hexagon to an internal pressure pulse. Plastic distortion of the cross section and large-deformation geometric effects that result in redistribution of the internal forces between bending and membrane stresses in the hexagon wall are included in the analytical model. Since the study is oriented toward removal problems of damaged subassemblies, only pressure pulses falling into categories 2 or 3 above will be considered.

The goals of the investigation are to (1) develop a computational procedure for determining the dynamic plastic response of a hexagon to an internal pressure pulse, (2) determine the effect of pulsc shape un the permanent deformation of the hexagon, (3) develop procedures for correlating permanent deformation with easily measured parameters associated with the pulse shape, (4) determine characteristic response times for plastic deformation of a hexagon, and (5) determine the relative magnitudes of dynamic deformation and static deformation produced by a given peak pressure.

A constraint on the goals of the investigation is that the computational methods and correlation procedures developed should be simple and easily applied. The aim is to provide the reactor engineer with a convenient tool for performing design-parameter studies, optimization analyses, safety studies, etc., where numerical analyses using, for instance, large finite-element programs may be excessively time-consuming and expensive. Moreover, the extension of general-purpose, finite-element programs to cover large dynamic plastic deformations is still in the development stage.

A presentation of the analysis and results of the study is divided between two reports. The first report, ${ }^{1}$. which is addressed to the first goal cited, contains (1) a description of the analytical model for the deforming 
hexagon, (2) details of the calculational procedure and computer program used to obtain numerical results, (3) an approximate closed-form solution valid in the small-deformation range, and (4) some typical results of the numerical computations.

This report describes the parameter studies performed to accomplish the remaining goals of the program. Section II contains a summary statement of the problem and the analytical model employed. Some typical results a re presented in Sec. III for the response of a hexagon to rectangular pulses. Section IV contains parameter studies of the response to rectangular pulses in the small-deformation range; in particular, the effect of the wall-thickness parameter is investigated and compaled with the results of the approximate solution derived in Ref. 1. In Sec. V, correlation procedures for the smalldeformation range are presented for relating arbitrary pulse shapes to equivalent rectangular pulses that produce the same permanent plastic deformation; characteristic response times are shown also. Section VI contains details of the large-deformation response of a hexagon to step pulses and.includes information on characteristic response times to long-duration pulses. Largedeformation results for various pulse shapes are compared in Sec. VII, and a procedure is given for relating arbitrary pulses to equivalent step pulses. Section VIII contains a dynamic-load-factor analysis for large-deformation response. Section IX presents an example of the method for bounding deformations produced by arbitrary pulses by those produced by equivalent rectangular pulses or step pulses. Finally, a summary and the conclusions of the study a re given in Sec. $X$.

\section{SUMMARY STATEMENT OF PROBLEM}

Figure l. shows a cross section of an internally pressurized hexagonal subassembly duct of wall thickness $H$ and side width $L$. The effect of axial

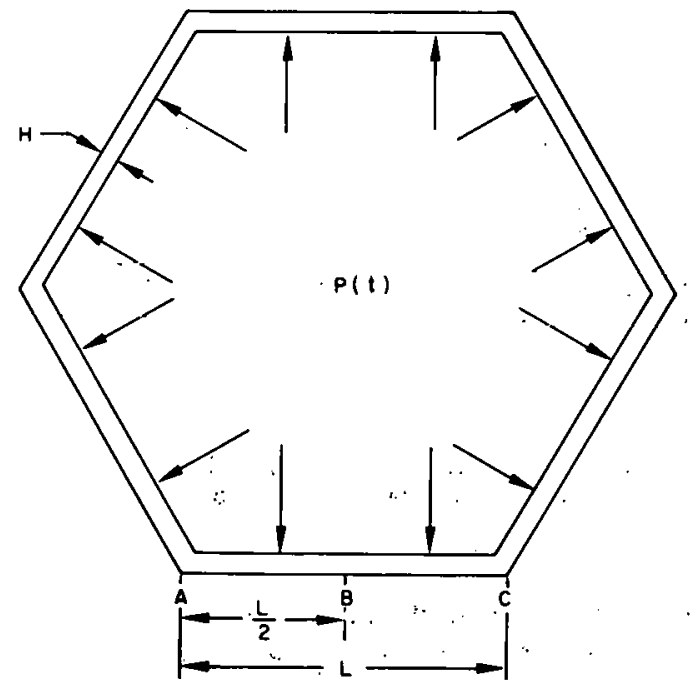

Fig. 1. Hexagon Subjected to Internal Pressurc Pulse. ANL Neg. No. 113-4090. variation of the deflection: shape is neglected, compared with the geometric effects of large distortion of the cross section. Consequently, the problem is reduced. to finding the dynamic plastic deformation of a hexagonal frame loaded by a time-dependent pressure $P(t)$. The redistribution of the dynamic loading between bending and membrane reactions as the deformation of the cross section proceeds is included in the analytical model for the large-deformation geometric effects.

The hexagon is assumed to be made - of a rigid, perfectly plastic material having yield stress $\sigma_{y}$. Elastic deformation is neglected, compared with the plastic deformation; strain hardening is neglected, 
compared with the large-deformation geometric effects. The yield condition, shown in Fig. 2 , is given by

$$
\frac{|\mathrm{M}|}{\mathrm{M}_{0}}+\frac{\mathrm{N}^{2}}{\mathrm{~N}_{0}^{2}}-1=0 \text {, }
$$

where $N$ and $M$ are, respectively, the resultant membrane force per unit axial length and bending moment per unit axial length arising from the stress distribution across the wall thickness at a plastically deforming location on the side of the hexagon; $N_{0}$ and $M_{0}$, the values of $N$ and $M$ for pure stretching and pure bending, respectively, are

$$
\mathrm{N}_{0}=\sigma_{\mathrm{y}} \mathrm{H}, \quad \mathrm{M}_{0}=\frac{\sigma_{\mathrm{y}} \mathrm{H}^{2}}{4}
$$

From Ref. 1, the initial limit load $P_{y}$, i.e., the limit load of the undistorted hexagon, is found to be

$$
P_{y}=\frac{8 H^{2} \sigma_{y}}{L\left(L+\sqrt{L^{2}+48 H^{2}}\right)} .
$$

The ratio $\mathrm{P}_{\mathrm{y}} / \sigma_{\mathrm{y}}$ is plotted as a function of hexagon wall thickness in Fig. 3 .

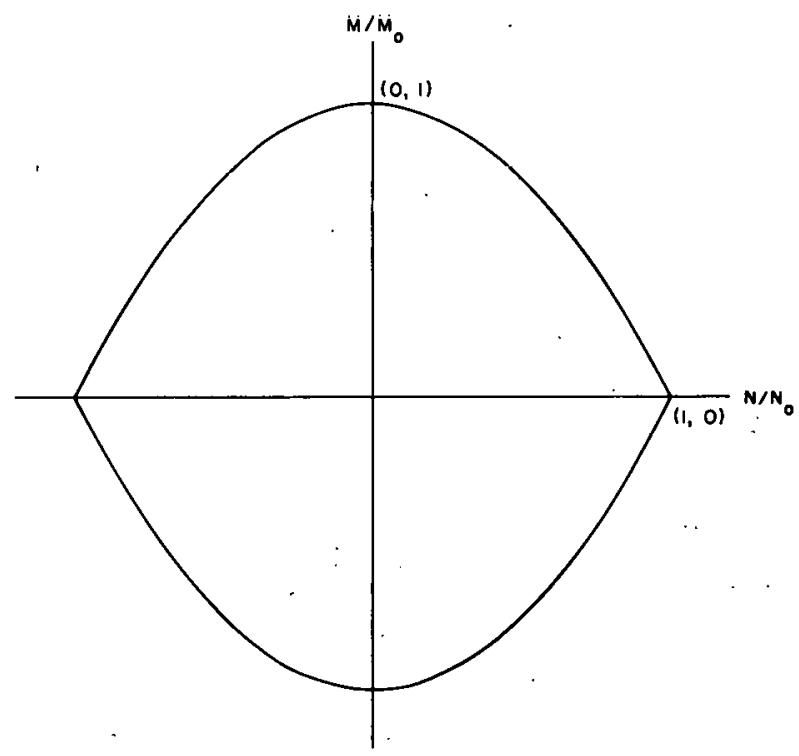

Fig. 2. Yield Condition: ANL Neg. No: 113-4049.

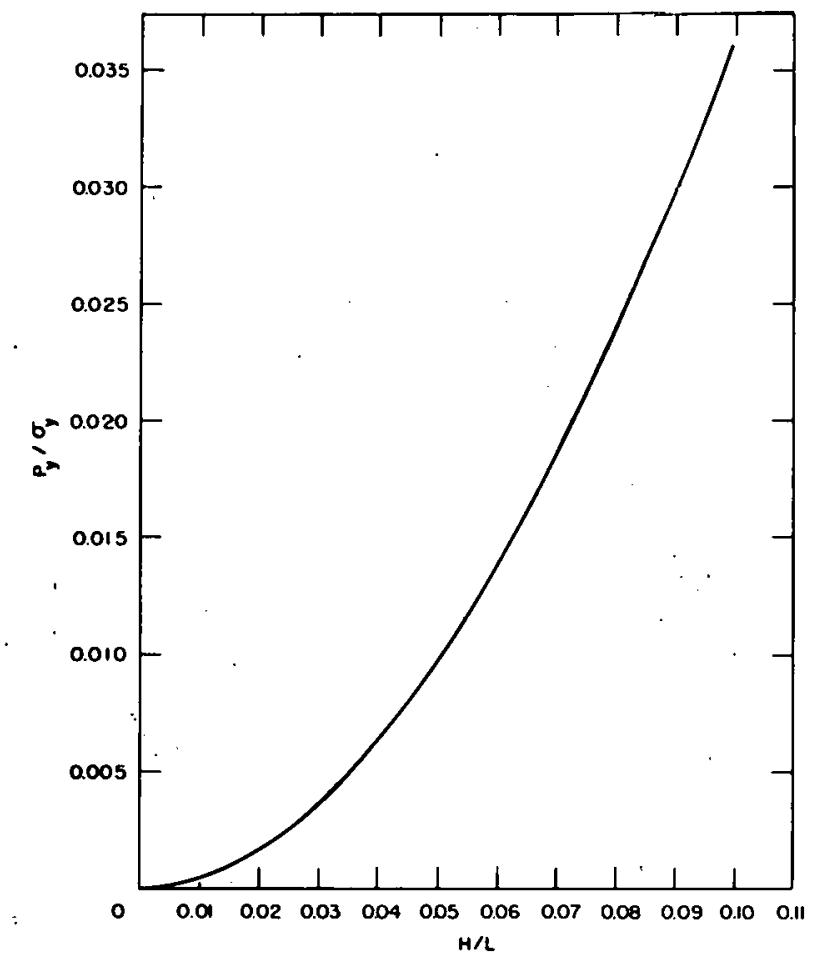

Fig. 3. Limit Load of Undistorted Hexagon. ANL Neg. No. 113-4236. 
Two possible plastic-deformation modes; each resulting in an irregular 12-sided figure, can be initiated by a pressure pulse. For each of these modes, the equilibrium equations, yield condition; plastic-flow rule; symmetry conditions, and compatability conditions comprise a set of coupled nonlinear differential equations. These sets a re solved numerically, using the computer program DYPLHX: The time-dependent behaviors of some of the variables involved are illustrated in Ref. I for some example problems.

Two variables of particular interest in this study are $U_{B}$, the outward deflection at the center of a side of the hexagon, and $U_{A}$, the outward deflection at a corner. Consequently, $2 U_{B}$ is the increase in dimension across flats of the hexagon, and $2 U_{A}$ is the increase in dimension across corners; a negative value for $U_{A}$, which occurs in some of the results presented, indicates that the corners move inward. Another quantity of interest is the response duration $t_{f}$, i.e., the time interval over which dynamic plastic deformation occurs. Where appearing, values of $U_{A}$ and $U_{B}$ at $t_{f}$ will be denoted by $U_{A f}$ and $U_{B f}$, respectively.

Important constants of the hexagon deformation model include a geometric parameter $\alpha$ and a time constant $t_{0}$, which a re defined by

$$
\left.\begin{array}{l}
\alpha=\mathrm{H} / \mathrm{L} \\
t_{0}=\mathrm{L} \sqrt{\frac{\rho}{\sigma_{\mathrm{y}}}}
\end{array}\right\}
$$

where $\rho$ is the density of the duct material. For an EBR-II subassembly duct, $\alpha=0.03$; for an FFTF subassembly duct, $\alpha=0.056$. Many of the results illus trated in this report are for these values of $\alpha$, which are taken to be typical of LMFBR core designs.

Figure 4 shows the time constant to as a function of yield stress $\sigma_{y}$ for stainless steel cans of EBR-II and FFTF size. The figure shows that to lies

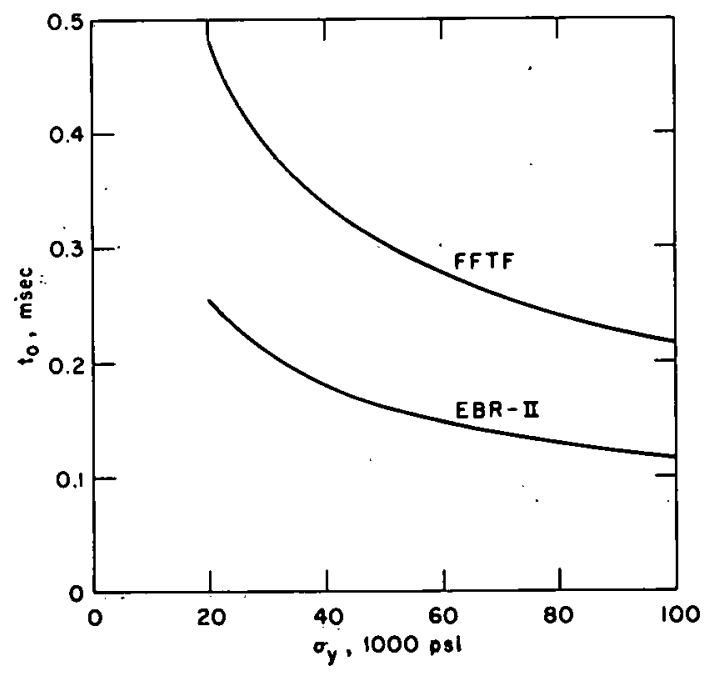

Fig. 4

Time Constant $t_{0}$ as a Function of Yield Stress for Typical Hexagonal Subassembly Ducts. ANL Neg. No. 113-4561. 
in the 0.1 - to 0.5 -msec range for typical duct configurations. This range for $t_{0}$ coincides with the range of pressure-pulse durations anticipated for fissiongas releases or fuel-coolant interactions. Pulse durations much less than to usually produce small deformations; pulse durations much larger than $t_{0}$ can be expected to produce essentially static response if the rise time of the pulse is long. It follows that the pressure-pulse durations most likely to occur in a subassembly duct are also those that fall in the intermediate range a round $t_{0}$ where dynamic analysis is essential.

Figure 5 shows pulse shapes for which results.will be presented. These include rectangular, step, exponential-decay, and linear-decay pulses.

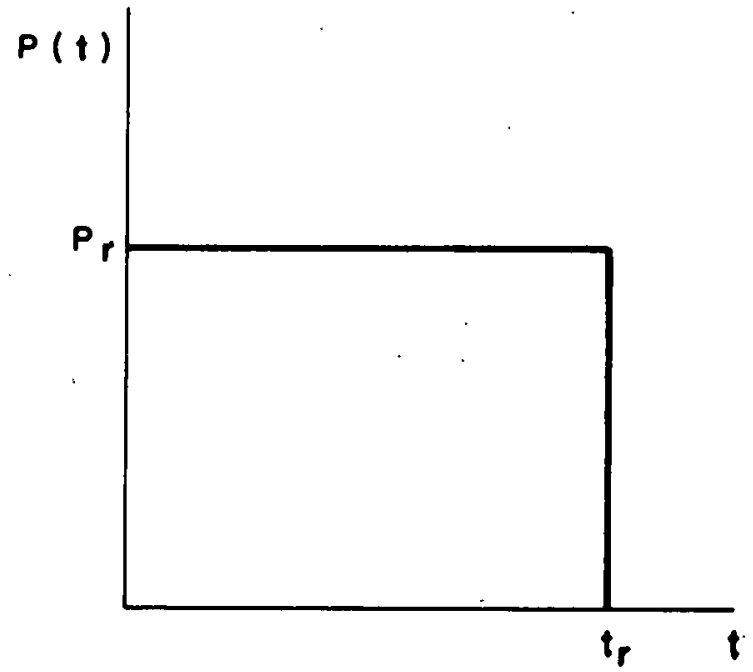

(a)

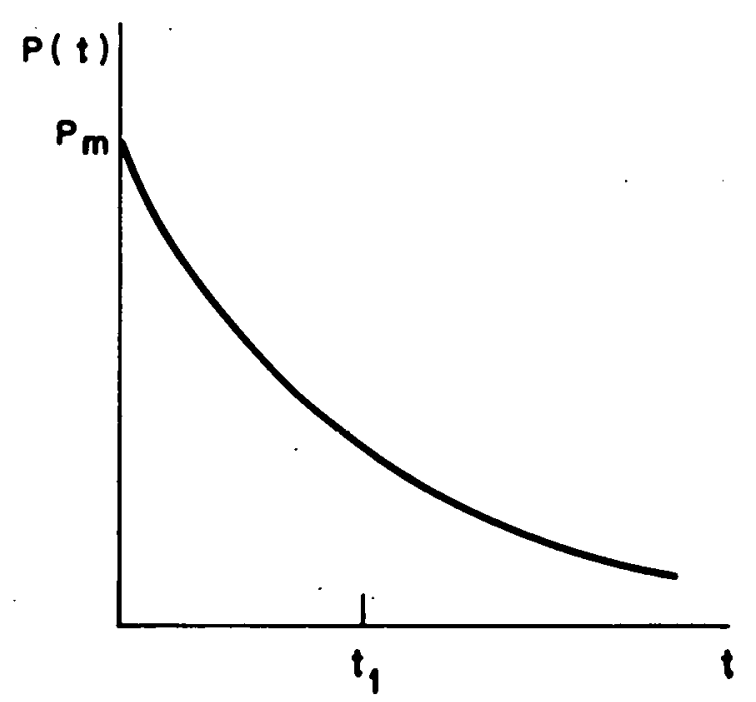

(c)

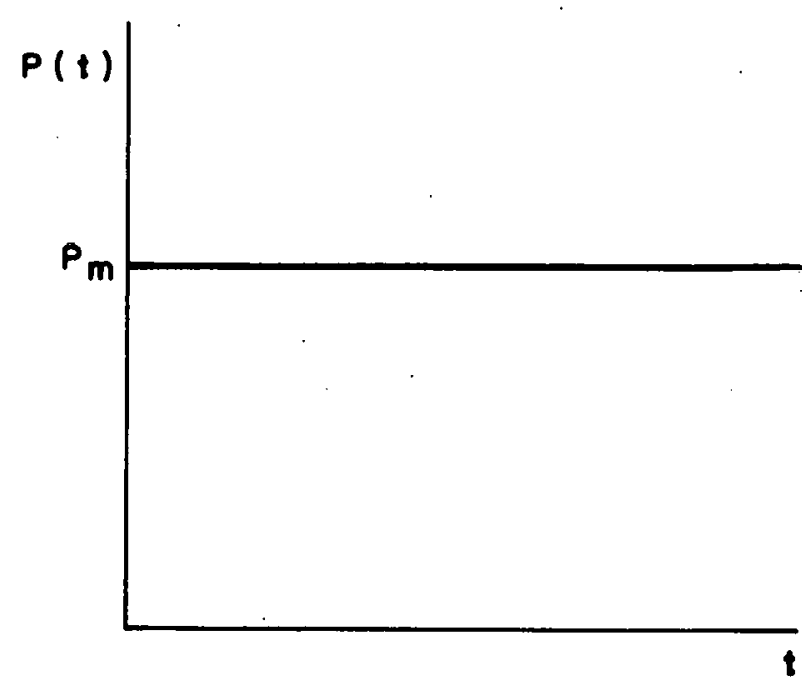

(b)

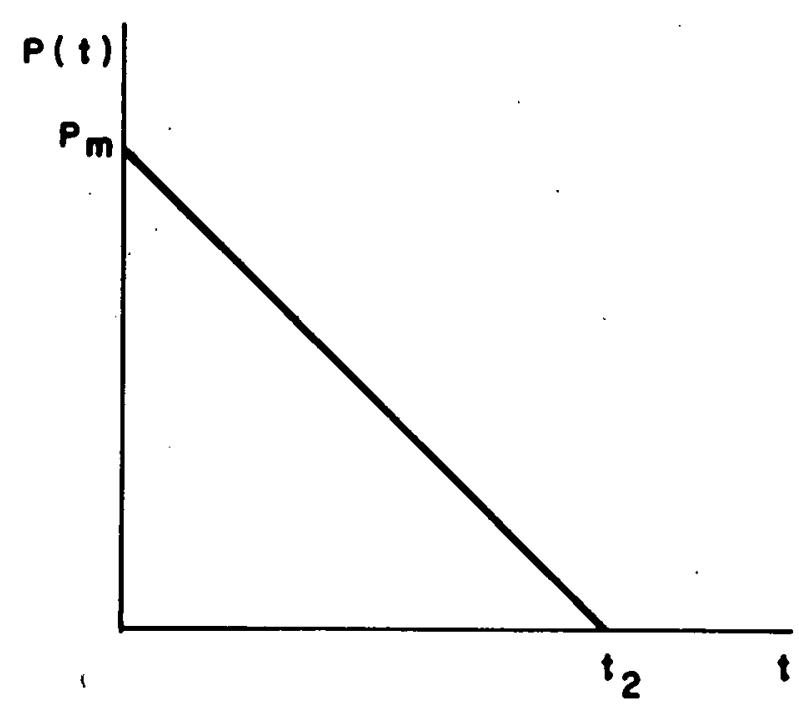

(d)

Fig. 5. Pulse Shapes: (a) Rectangular pulse; (b) step pulse; (c) exponential-decay pulse; and (d) linear-decay pulse. ANL Neg. No. 113-4564. 


\section{CHARACTERISTICS OF RESPONSE TO RECT ANGULAR PU LSES}

Some general characteristics of the dynamic plastic response of a hexagon to rectangular pulses will be discussed in this section.

Consider a rectangular pulse (see Fig. 5a) defined by.

$$
\left.\begin{array}{l}
P(t)=P_{r}, \quad 0 \leq t \leq t_{r} \\
P(t)=0, \quad t<0, \text { and } t>t_{r} .
\end{array}\right\}
$$

Figures 6 and 7 show the midside deflection $U_{B}$ divided by the wall thickness as a function of time for $\alpha=0.03$ and $\alpha=0.056$, respectively. The pulse magnitude $P_{r}$ is taken to be $2 P_{y}$. Since $P_{y}$ is a function of $\alpha$ (given by Fig. 3 and Eq. 3), $\mathrm{Pr}_{\mathrm{r}}=0.00712 \sigma_{\mathrm{y}}$ in Fig. 6, and $\mathrm{Pr}_{\mathrm{r}}=0.02421 \sigma_{\mathrm{y}}$ in Fig. 7 . Results are plotted for various values of $t_{r} / t_{0}$. The final deflection and the response duration correspond to the end point of each curve.

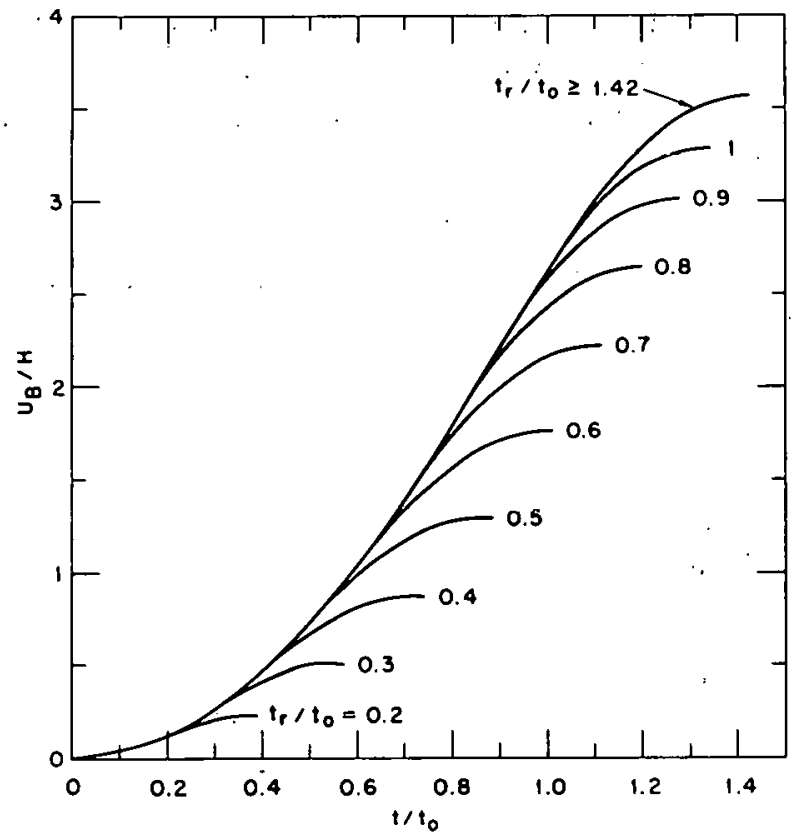

Fig. 6. Midside Deflection as a Function of Time for Reçtangular Pulses of Various Durations: $\alpha=0.03, \mathrm{P}_{\mathrm{r}}=2 \mathrm{P}_{\mathrm{y}}=0.00712 \sigma_{\mathrm{y}}$. ANL Neg. No. 113-4556 Rev. 1.

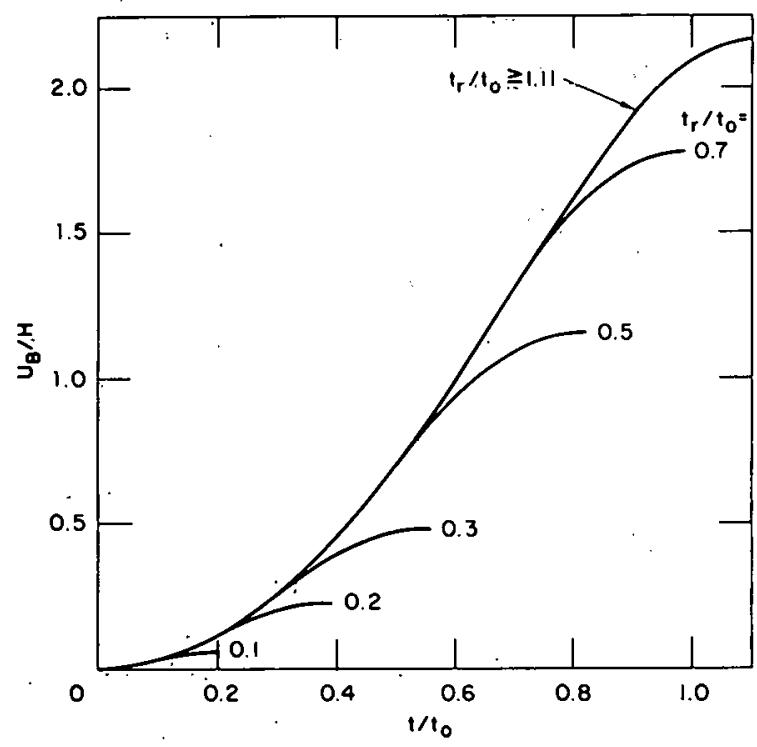

Fig. 7. Midside Deflection as a Function of Time for Rectangular Pulses of Various Durations: $\alpha=0.056, \mathrm{P}_{\mathrm{r}}=2 \mathrm{P}_{\mathrm{y}}=0.02421 \sigma_{\mathrm{y}}$. ANL Neg. No. 113-4248 Rev. 1.

From Fig. 6 we see that as the pulse duration is increased, the final deflection and the response duration $t_{f}$ increase until $t_{r} / t_{0}=1.42$. For values of $t_{r}$ greater than $1.42 t_{0}$, the deformation stops before the end of the pulse, because the hexagon is distorted into a shape that can statically withstand the applied pressure. ${ }^{*}$ Consequently, if $t_{r}$ is sufficiently large, the response to a

\footnotetext{
* Because of the kinetic energy involved in the dynamic deformation, the distortion exceeds the amount necessary to contain the applied pressure statically. (See Sec. VIII and Ref. 1 for details on the static containment potential of a deformed hexagon.)
} 
rectangular pulse is identical to the response to a step pulse of the same magnitude. The maximum midside deflection is about 3.6 times the wall thickness for this combination of $\mathrm{P}_{\mathrm{r}}$ and $\alpha$.

The results for $\alpha=0.056$ are qualitatively similar to those for $\alpha=$ 0.03 , as can be seen from Fig. 7. For $t_{r}<1.11 t_{0}$, the response duration $t_{f}$ is greater than $t_{r}$. Conversely, for $t_{r}>1.11 t_{0}$, the response duration is less than $t_{r}$; in fact, $t_{f}=1.11 t_{0}$ for all rectangular pulses with $t_{r} \geq 1.11 t_{0}$ and $P_{r}=$ $0.0242 l \sigma_{y}$ (including the limiting case of a step pulse with this magnitude), and all such pulses produce the same deformation response. The maximum permanent deformation is about 2.2 times the wall thickness for the combination of $P_{r}$ and $\alpha$ shown.

The corner displacement of the hexagon caused by rectangular pulses is given in Figs. 8 and 9 as a function of time for the values of $P_{r}$ and $\alpha$ of Figs. 6 and 7. Again, results are shown for various values of pulse duration, and the response duration is indicated by the end point of each curve. The values of $U_{A}$ are negative, i.e., the corners move inward, except for very small values of $t / t_{0}$ when $U_{A}$ is positive (which does not show up on the scale to which the figures are drawn). The maximum inward displacement of the corners is about 1.12 times the wall thickness for $\alpha=0.03$ and about 0.51 times the wall thickness for $\alpha=0.056$, with $\mathrm{P}_{\mathrm{r}}$ equal to twice the yield pressure for the respective value of $\alpha$.

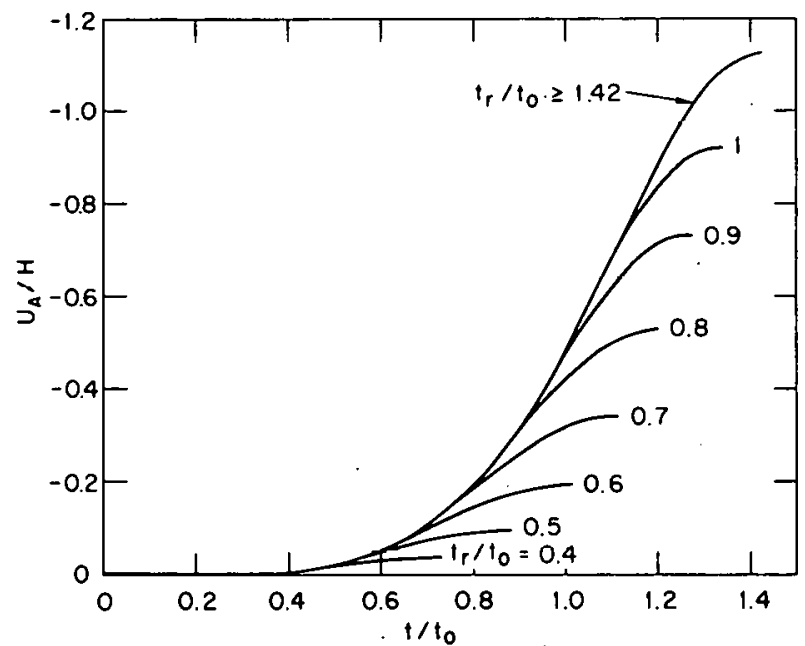

Fig. 8. Corner Deflection as a Function of Time for Rectangular Pulses of Various Durations: $\alpha=0.03, \mathrm{P}_{\mathrm{I}}=2 \mathrm{P} \mathrm{y}=0.00712 \sigma_{\mathrm{y}} . \mathrm{ANL}$ Neg. No. 113-4562 Rev. 1.

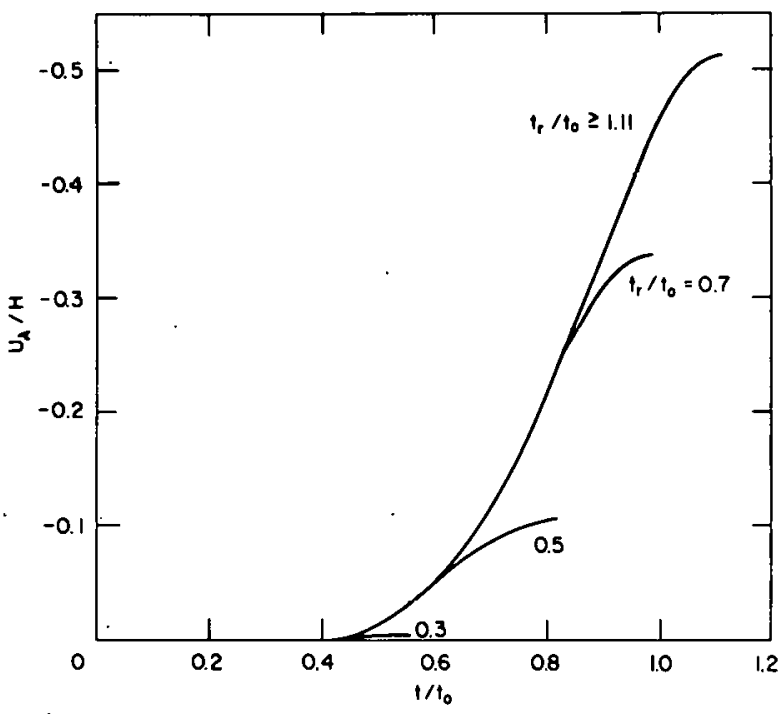

Fig. 9. Corner Deflection as a Function of Time for Rectangular Pulses of Various Durations: $\alpha=0.056, P_{r}=2 P_{y}=0.02421 \sigma_{y}$. ANL Neg. No. 113-4558 Rev. 1.

Figures 10 and 11 show the final midside deflection and the response duration plotted on a log-log scale as functions of rectangular-pulse duration for the same combinations of $\mathrm{P}_{\mathbf{r}}$ and $\alpha$ as the preceding figures. The 
$\log -\log$ plots reveal qualitative differences in the dependence on pulse duration for the small - and large-deformation ranges: In the small-deformation range, the curves for $t_{f} / t_{0}$ and $U_{B f} / H$ are straight lines with slopes of 1 and 2 , respectively; this means that $t_{f}$ is directly proportional to $t_{r}$ and $U_{B f}$ varies as $t_{r}^{2}$. In the large-deformation range, the curves bend over and become perfectly flat at the point where $t_{f}=t_{r}$, beyond which the response to a. rectangular. pulse is identical to that to a step pulse.

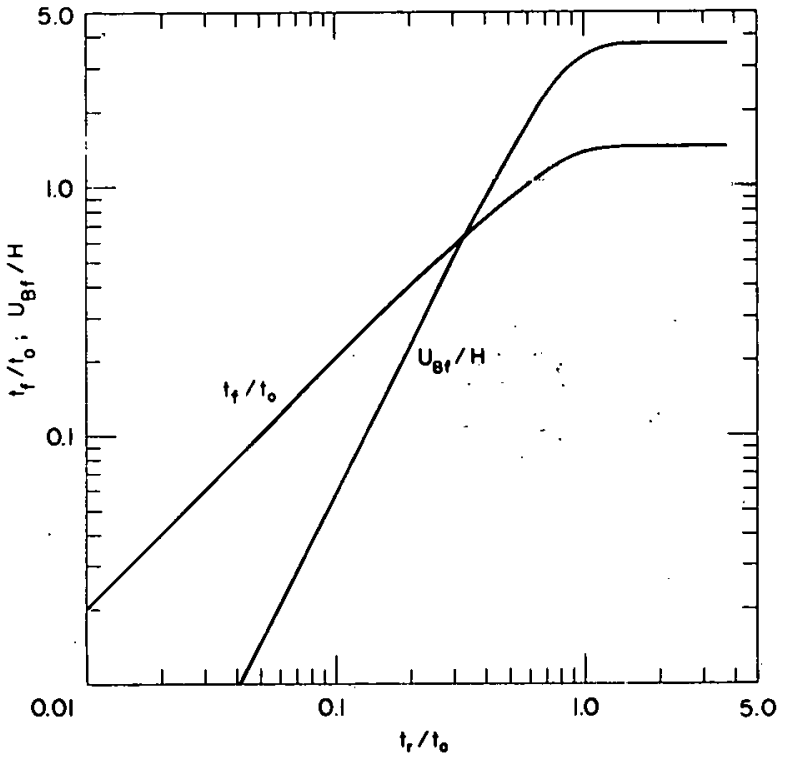

Fig. 10. Final Midside peflection and Response Duration as Functions of Rectangular-pulse Durations: $\alpha=0.03, \mathrm{P}_{\mathrm{r}}=2 \mathrm{P}_{\mathrm{y}}=0.00712 \sigma_{\mathrm{y}}$. ANL Neg. No. 113-4565 Rev. 1.

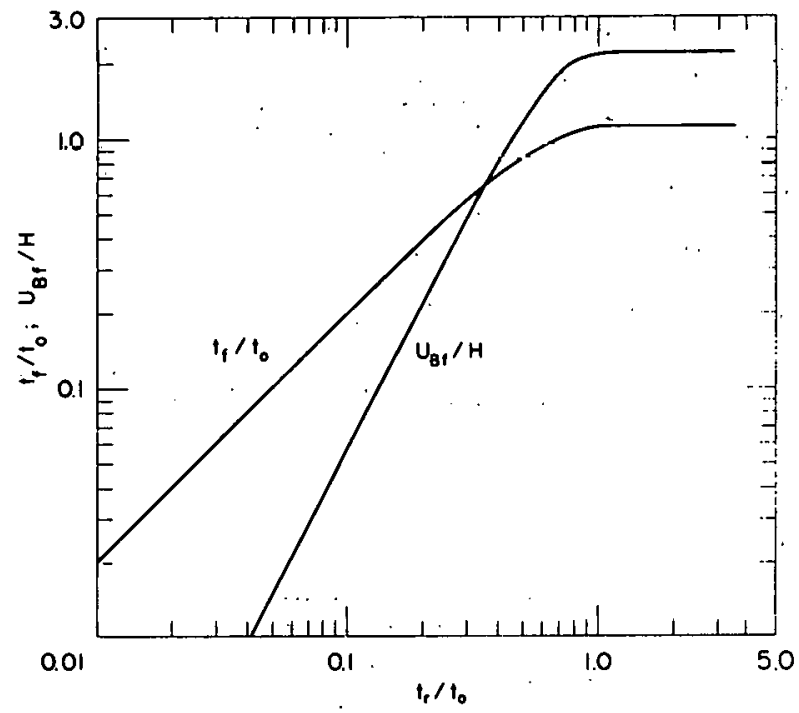

Fig. 11. Final Midside Deflection and Response Duration as Functions of Rectangular-pulse Durations: $\alpha=0.056, \mathrm{P}_{\mathrm{I}}=2 \mathrm{P}_{\mathrm{y}}=0.02421 \sigma_{\mathrm{y}}$. ANL Neg. No. 113-4484 Rev. 1.

Small-deformation response is discussed in more detail in Secs. IV and $V$, and large-deformation response is covered in Secs. VI-VIII.

\section{RECTANGU LAR-PULSE RESPONSE IN SMALL-DEFORMATION RANGE}

An approximate solution for small-deformation response to rectangular pulses is derived in closed form in Ref. 1. This approximate solution was shown to closely match the numerical solution of the governing nonlinear differential equations if $t_{r} / t_{0}$ is small. The approximations for $U_{B f}$ and $t_{f}$ will be repeated here for easy reference.

The form of the approximate solution depends on whether $P_{r}$ is greater or less than $\mathrm{P}_{\mathrm{h}}^{*}$, where $\mathrm{e}^{\dagger}$ :

$$
\mathrm{P}_{\mathrm{h}}^{*}=\frac{24 \alpha^{2} \sigma_{\mathrm{y}}}{1+\sqrt{1+108 \dot{\alpha}^{2}}}
$$

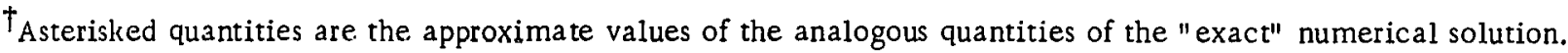


$P_{h}$ is the dividing line between initial first plastic-deformation-mode response and initial second plastic-deformation-mode response, where the modes are defined in Ref. 1 .

$$
\begin{aligned}
& \text { For } P_{\cdot r}=P_{h}^{*} \\
& t_{f}^{*}=t_{r}\left(1+\frac{f_{1}}{f_{2}}\right)
\end{aligned}
$$

and

$$
U_{B f}^{*}=\frac{H f_{1} t_{r}^{2}}{t_{0}^{2}}\left(1+\frac{f_{1}}{f_{2}}\right),
$$

where

$$
f_{1}=\frac{P_{r}}{\alpha^{2} \sigma_{y}}-6\left(1+\frac{P_{r}}{12 \alpha^{2} \sigma_{y}}\right) /\left(1+\sqrt{1+27 \alpha^{2}+\frac{9 P_{r}}{4 \sigma_{y}}}\right)
$$

and

$$
f_{2}=\frac{6}{1+\sqrt{1+27 \alpha^{2}}}
$$

Moreover, as $\alpha \rightarrow 0$,

$$
\begin{aligned}
t_{f}^{*} & \rightarrow t_{r} \frac{P_{r}}{P_{y}} \\
U_{B f}^{*} & \rightarrow 3 H\left(\frac{P_{r} t_{r}}{P_{y} t_{0}}\right)^{2}\left(1-\frac{P_{y}}{P_{r}}\right) .
\end{aligned}
$$

and

$$
\mathrm{P}_{\mathrm{h}}^{*} \rightarrow 3 \mathrm{P}_{\mathrm{y}} \text {. }
$$

For $\mathrm{P}_{\mathrm{r}}>\mathrm{P}_{\mathrm{h}}^{*}$

$$
t_{f}^{*}=t_{r}\left[\frac{P_{r}}{2 \alpha^{2} \sigma_{y}}\left(\frac{1}{f_{2}}+\frac{1}{24}\right)+1-\frac{1}{4+9 \frac{P_{r}}{\sigma_{y}}}\right] .
$$

and

$$
\mathrm{U}_{\mathrm{Bf}}^{*}=\frac{\mathrm{Ht}_{\mathrm{r}}^{2}}{\mathrm{t}_{0}^{2}}\left[\left(\frac{\mathrm{P}_{\mathrm{r}}}{2 \alpha^{2} \sigma_{\mathrm{y}}}\right)^{2}\left(\frac{1}{\mathrm{f}_{2}}+\frac{1}{12}\right)+\frac{\mathrm{P}_{\mathrm{r}}}{\alpha^{2} \sigma_{\mathrm{y}}}\left(\frac{1}{2}-\frac{1}{4+9 \frac{\mathrm{P}_{\mathrm{r}}}{\sigma_{\mathrm{y}}}}\right)\right]
$$


and; as $\alpha \rightarrow 0$,

$$
t_{\mathrm{f}}^{*} \rightarrow \frac{3 t_{r}}{4}\left(1+\frac{P_{r}}{P_{y}}\right)
$$

and

$$
U_{B f}^{*} \rightarrow H\left(\frac{P_{r} t_{r}}{P_{y} t_{0}}\right)^{2}\left(\frac{5}{3}+\frac{P_{y}}{P_{r}}\right) .
$$

As as example of the closeness of the approximate solution to the "exact" solutiun, consider the resil.ts shown in Fig. 12. The quantity

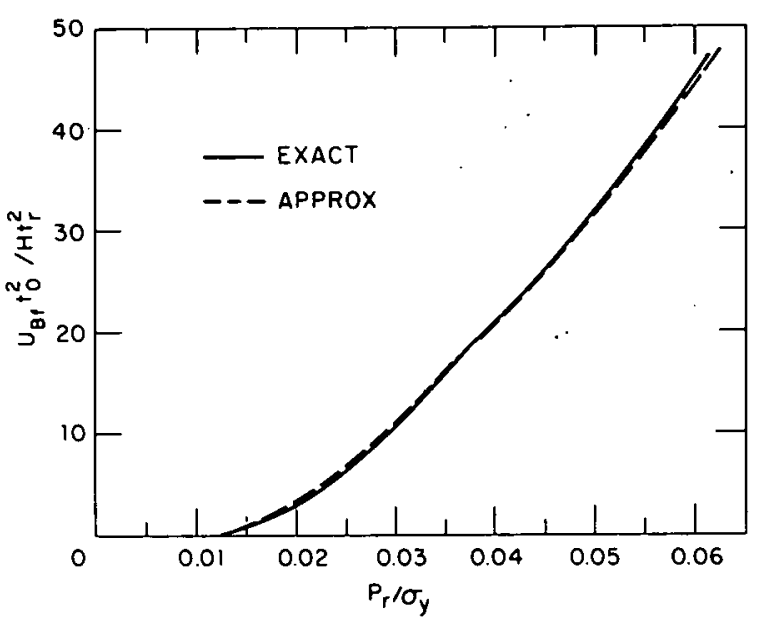

Fig. 12. Comparison of Exact and Approximate Solutions for Response to Rectangular Pulse in Small-deformation Range: $\alpha=0.056$. ANL Neg. No. 113-4242 Rev. 2.

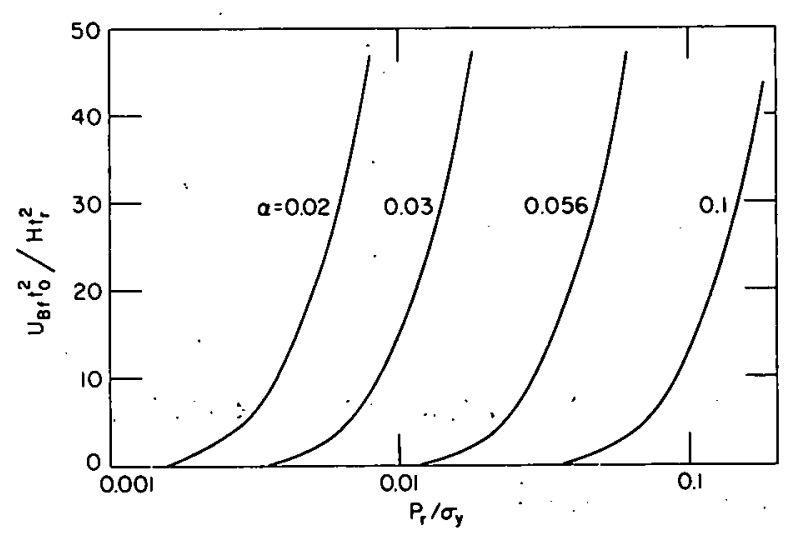

Fig. 13. $\mathrm{U}_{\mathrm{Bft}}^{2} / \mathrm{Ht}_{\mathrm{r}}^{2}$ as a Function of $\mathrm{P}_{\mathrm{I}} / \sigma_{\mathrm{y}}$ in Smalldeformation Range for Various $\alpha$. ANL Neg. No. .113-4567 Rev. 1.
$\mathrm{UBft}_{0}^{2} / \mathrm{Ht}_{\mathbf{r}}^{2}$ (as suggested by the analysis of the curves of Figs. 10 and 11) is plotted as a function of $\mathrm{P}_{\mathrm{r}} / \sigma_{\mathrm{y}}$ for the approximate solution given by Eqs. 7 and 10 and for the computer solution for $t_{r} / t_{0}=0.01 ; \alpha$ is taken to be. 0.056 . Comparisons for other values of $\alpha$ are equally good. Consequently, the approximate solution for rectangular pulses can be used whenever convenient, if $t_{r} / t_{0}$ is small enough that the response is in the small-deformation range.

In Fig. 13, the quantity $\mathrm{U}_{\mathrm{Bf}} \mathrm{t}_{0}^{2} / \mathrm{Ht}_{\mathrm{r}}^{2}$ is plotted as a function of $\log \left(\mathrm{P}_{\mathrm{r}} / \sigma_{\mathrm{y}}\right)$ for a wide rangett of values of $\alpha$. Even on a logarithmic scale the curves are spread out. However, when plotted as a function of $\mathrm{P}_{\mathrm{r}} / \mathrm{P}_{\mathrm{y}}$ (see Fig. 14), the curves

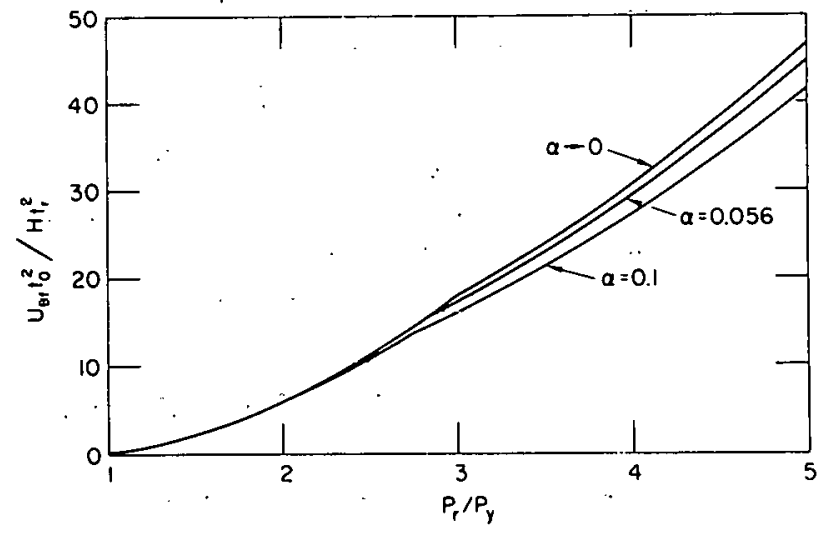

Fig. 14. $\mathrm{U}_{\mathrm{Bft}}^{2} / \mathrm{Ht}_{\mathrm{r}}^{2}$ as a Function of $\mathrm{P}_{\mathrm{r}} / \mathrm{P}_{\mathrm{y}}$ in Smalldeformation Range for $V$ arious $\alpha$. ANL Neg. No. 113-4481 Rev. 1 .

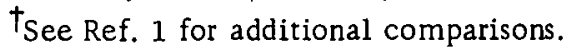

$\dagger^{\dagger}$ For typical reactor core designs, $\alpha$ would not be expected to exceed 0.1 . 
are very close together. This implies that the simple expressions given in Eqs. 9 and 11 for $\alpha \rightarrow 0$ can be used for other values of $\alpha$ if (a) the response is in the small-deformation range and (b) the results are plotted as functions of $\mathrm{P}_{\mathrm{r}} / \mathrm{P}_{\mathrm{y}}$, where $\mathrm{P}_{\mathrm{y}}$ is computed for the actual value of $\alpha$.

Figure 15 shows the ratio $t_{f} / t_{r}$ of response duration to pulse duration as a function of $P_{r} / P_{y}$ for a range of values of $\alpha$; $t_{r}$ is small enough that the response is in the small-deformation range. Again, we see that the simple result for $\alpha \rightarrow 0$ given in Eqs. 9 and 11 can be used for other values of $\alpha$ if $P_{y}$ is computed using the actual value of $\alpha$ for the problem. The same information is plotted in the form $P_{y} t_{f} / P_{r} t_{r}$ as a function of $P_{r} / P_{y}$ in Fig. 16. It is apparent that

$$
\mathrm{P}_{\mathrm{y}} \mathrm{t}_{\mathrm{f}} \approx \mathrm{P}_{\mathrm{r}} \mathrm{t}_{\mathrm{r}}
$$

for a significant range of values of $P_{r} / P_{y}$. This relation has the physical interpretation that the applied impulse $\mathrm{P}_{\mathrm{r}} \mathrm{t}_{\mathrm{r}}$ is absorbed by a plastic resistance $P_{y}$ over an interval $t_{f}$.

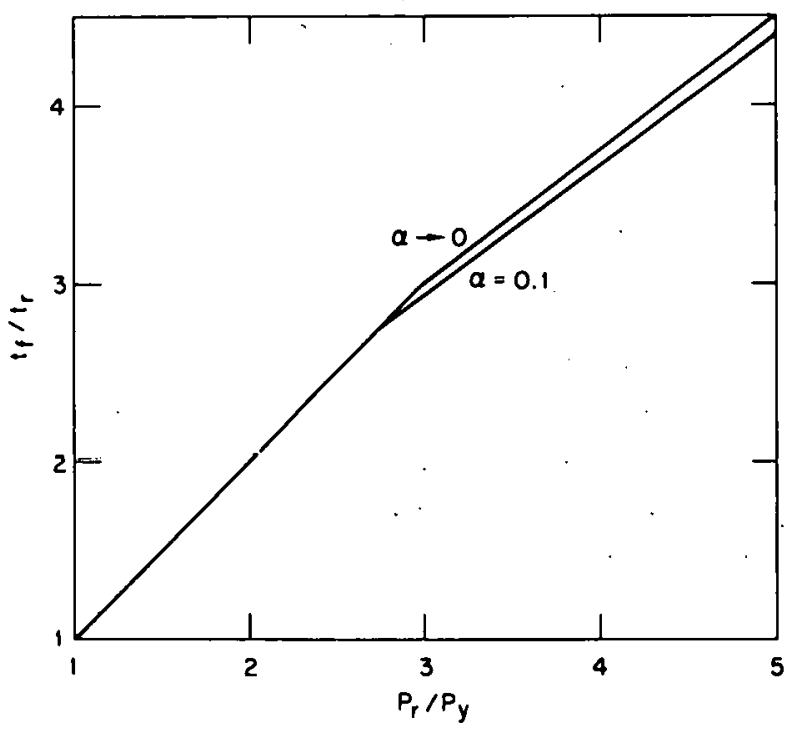

Fig. 15. Ratio of Response Duration to Pulse Duration as a Function of $\mathrm{P}_{\mathrm{r}} / \mathrm{P}_{\mathrm{y}}$ in Small-deformation Range. ANL Neg. No. 113-4477.

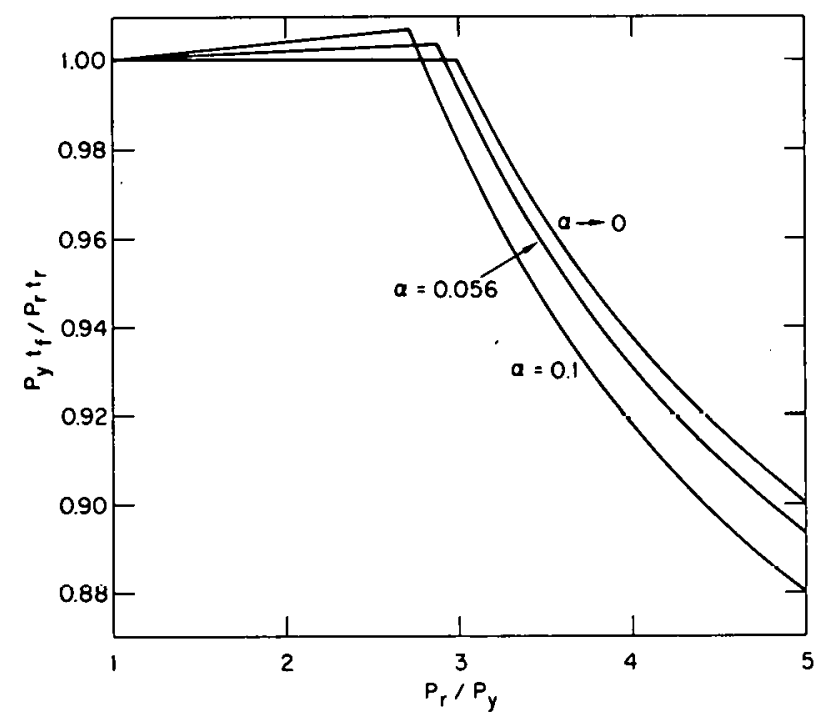

Fig. 16. $\mathrm{P}_{\mathrm{y}} \mathrm{t}_{\mathrm{f}} / \mathrm{P}_{\mathbf{r}} \mathrm{t}_{\mathrm{r}}$ as a Function of $\mathrm{P}_{\mathrm{r}} / \mathrm{P}_{\mathrm{y}}$ in Small-deformation Range. ANL Neg. No. 113-4560.

\section{EFFECT OF PULSE SHAPE IN SMALL-DEFORMATION RANGE}

The effect of pulse shape on permanent plastic deformation has been investigated for a variety of structural configurations. ${ }^{2,3}$ These configurations include: a uniformly loaded, simply supported circular plate; a uniformly pressurized, reinforced circular cylindrical shell; a beam subjected to a dynamic central force; a long circular tube subjected to a dynamic ringload; and a long tube loaded by a dynamic axially varying pressure. The deformations 
were assumed to be small for each problem, and the structures were assumed to be made of rigid, perfectly plastic materials. Closed-form solutions for arbitrary pulse shapes were derived from some of these problems; the others were solved numerically.

Let $\mathscr{L}(\mathrm{t})$ be the applied loading, which may be a time-dependent pressure or force, and let $\mathrm{U}_{0}$ be the maximum permanent plastic deformation of the structure. Then

$$
\mathrm{U}_{0}=\mathrm{F}[\mathcal{L}(\mathrm{t})]
$$

where $\Gamma$ is a functionil. The conclusion of these investigations was that $U_{0}$ could be approximated by

$$
\mathrm{U}_{0} \approx \mathrm{I}^{2} \mathrm{f}\left(\mathscr{L}_{\mathrm{e}}\right)
$$

where $f$ is a function, I is the impulse, and $\mathscr{L}_{\mathrm{e}}$ is an effective value of the load. In other words, the arbitrary loading $\mathcal{L}(\mathrm{t})$ can be replaced by an effective rectangular pulse of height $\mathscr{L}_{\mathrm{e}}$ and duration $t_{e}$, where

$$
\mathrm{t}_{\mathrm{e}}=\mathrm{I} / \mathscr{L}_{\mathrm{e}}
$$

The impulse and effective load are defined by

$$
I=\int_{t_{y}}^{t_{f}} \mathscr{L}(t) d t
$$

and

$$
\left.\mathscr{L}_{\mathrm{e}}=\frac{\mathrm{I}}{2 \mathrm{t}_{\text {mean }}},\right\}
$$

$t_{y}$ and $t_{f}$ being the times when plastic deformation begins and ends, respectively, and $t_{\text {mean }}$ being the location of the centroid of the pulse measured from $t_{y}$ (see Fig. 17). By definition,

$$
\mathrm{t}_{\text {mean }}=\frac{1}{\mathrm{I}} \int_{\mathrm{t}_{\mathrm{y}}}^{\mathrm{t}_{\mathrm{f}}}\left(\mathrm{t}-\mathrm{t}_{\mathrm{y}}\right) \mathscr{L}(\mathrm{t}) \mathrm{dt} .
$$

The initial time $t_{\mathrm{y}}$ is when $\mathscr{L}(\mathrm{t})$. first attains the value $\mathscr{L}_{\mathrm{y}}$, the plastic limit load. The final time $t_{f}$ is determined from the relation

$$
\mathrm{I} \approx \mathscr{L}_{\mathrm{y}}\left(\mathrm{t}_{\mathrm{f}}-\mathrm{t}_{\mathrm{y}}\right)
$$

which is exactly true for some of the problems studied and approximately true for the others (see also Eq. 12). From Eqs. 15 and 16, we have :

$$
t_{e}=2 t_{\text {mean }} .
$$




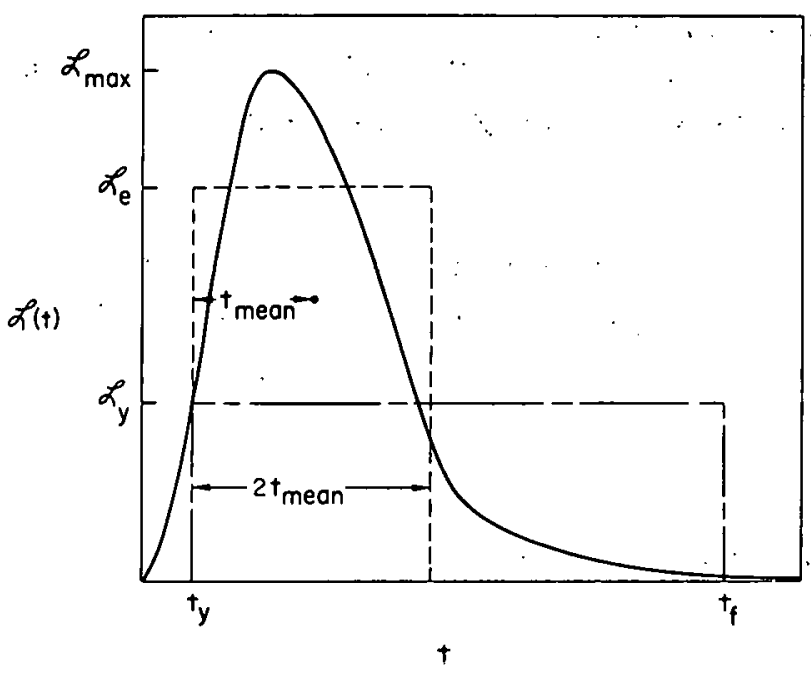

Fig. 17

Pulse Parameters for Arbitrary Pulse. ANL Neg. No. 113-4262.

The same correlation procedure between permanent plastic deformation and pulse shape is valid for the deforming hexagon. By Eq. $14, \mathrm{UBf} / \mathrm{I}^{2}$ should be approximately a function of an effective pressure $P_{e}$, regardless of pulse shape. In order to deal with nondimensional quantities, we will consider the dependence of $\left(\mathrm{U}_{\mathrm{Bf}} / \mathrm{H}\right)\left(\mathrm{P}_{\mathrm{y}} \mathrm{t}_{0} / \mathrm{I}\right)^{2}$ on $\mathrm{P}_{\mathrm{e}} / \mathrm{P}_{\mathrm{y}}$ and $\mathrm{P}_{\mathrm{m}} / \mathrm{P}_{\mathrm{y}}$, where $\mathrm{P}_{\mathrm{m}}$ is the peak pressure of the pulse. By analogy to Eqs. 16, 17, and 19, we will define $I, P_{e}$, and $t_{e}$ for the deforming hexagon by

$$
\begin{aligned}
I & =\int_{0}^{t_{f}} P(t) d t \\
P_{e} & =I / t_{e}
\end{aligned}
$$

and

$$
t_{e}=2 t_{\text {mean }},
$$

whe re

$$
t_{\text {mean }}=\frac{1}{I} \int_{0}^{t_{f}} t P(t) d t .
$$

It has been assumed here that time is measured from the instant when plastic deformation begins; i.e., $t_{y}=0$.

Figures 18 and 19 show $\left(\mathrm{U}_{\mathrm{Bf}} / \mathrm{H}\right)\left(\mathrm{P}_{\mathrm{y}} \mathrm{t}_{\mathrm{o}} / \mathrm{I}\right)^{2}$ as a function of $\mathrm{P}_{\mathrm{m}} / \mathrm{P}_{\mathrm{y}}$ and $\mathrm{P}_{\mathrm{e}} / \mathrm{P}_{\mathrm{y}}$, respectively, for $\alpha=0.03$. Curves are shown for rectangular pulses, exponential-decay pulses, and linear-decay pulses (see Figs. 5a, c, and d). The pulses are given by:

Rectangular pulse

$$
\left.\begin{array}{rlrl}
P(t) & =P_{m}, & 0 \leq t \leq t_{r} ; \\
& =0, & t>t_{r} .
\end{array}\right\}
$$


Exponential-decay pulse

$$
P(t)=P_{m} e^{-t / t_{1}}, \quad 0 \leq t<\infty .
$$

Linear-decay pulse

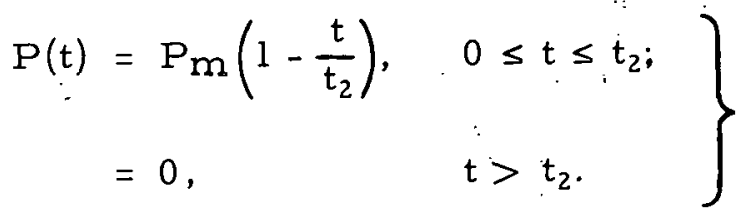

The approximate sulution computed from Eqs. 8 and 10 is also shown in. Fig. 19.

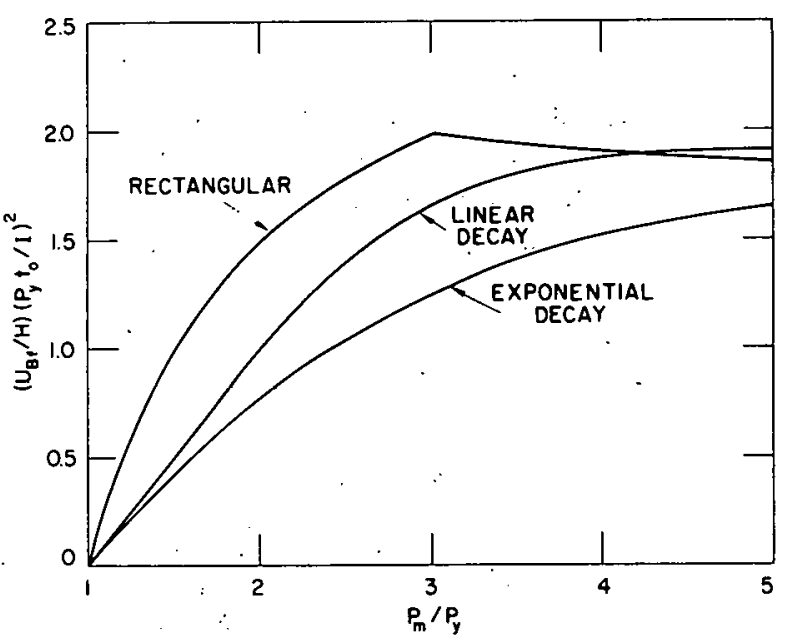

Fig. 18. $\left(\mathrm{U}_{\mathrm{Bf}} / \mathrm{H}\right)\left(\mathrm{P}_{\mathrm{y}} \mathrm{t}_{0} / \mathrm{I}\right)^{2}$ as a Function of $\mathrm{P}_{\mathrm{m}} / \mathrm{P}_{\mathrm{y}}$ in Small-deformation Range for Several Pulse Shapes: $\alpha=0.03$. ANL Neg. No. 113-4483 Rev. 1.

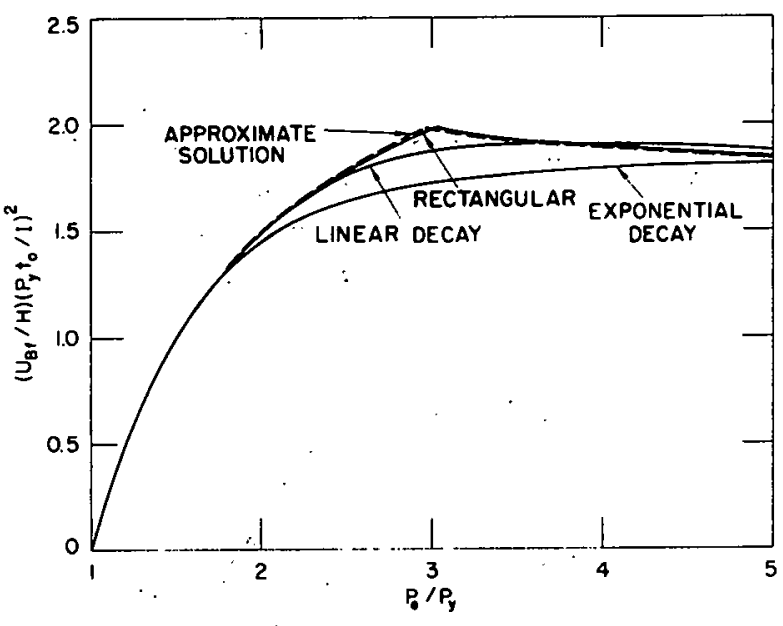

Fig. 19. $\left(\mathrm{U}_{\mathrm{Bf}} / \mathrm{H}\right)\left(\mathrm{P}_{\mathrm{y}} \mathrm{t}_{0} / \mathrm{I}\right)^{2}$ as a Function of $\mathrm{P}_{\mathrm{e}} / \mathrm{P}_{\mathrm{y}}$ in Small-deformation Range for Several Pulse Shapes: $\alpha=0.03$. ANL Neg. No. 113-4482 Rev. 1.

From Fig. 18 we see that the final deflection is strongly dependent on the pulse shape, even for pulses having the same peak value and impulse. At $\mathrm{P}_{\mathrm{m}}=2 \mathrm{P}_{\mathrm{y}}$, for example, the deformation produced by a rectangular pulse is roughly twice that produced by an exponential-decay pulse: Plotting the same deformations as a function of the effective pressure, as in Fig. 19, comprcsses the curves together. This indicates that the effect of pulse shape can be essentially eliminated by taking

$$
\frac{\mathrm{U}_{\mathrm{Bf}}}{\mathrm{H}} \approx\left(\frac{\mathrm{I}}{\mathrm{P}_{\mathrm{y}} \mathrm{t}_{0}}\right)^{2} \mathrm{f}\left(\mathrm{Pe}_{\mathrm{e}} / \mathrm{P}_{\mathrm{y}}\right)
$$

Figures 20 and 21 show similar results for $\alpha=0.056$ :

To obtain a relation for $\mathrm{t}_{\mathrm{f}}$ similar to that of $\mathrm{Eq} \cdot 18, \mathrm{t}_{\mathrm{f}} \mathrm{P}_{\mathrm{y}} / \mathrm{I}$ is plotted as a function of $\mathrm{P}_{\mathrm{e}} / \mathrm{P}_{\mathrm{y}}$ for $\alpha=0.03$ and $\alpha=0.056$ in Figs. 22 and 23 , respectively, for various pulse shapes. We see that $t_{f} P_{y} / I$ is close to unity for a 
range of values of $P_{e} / P_{y}$, and that the curve for the approximate solution is a reasonable representation for the other curves.

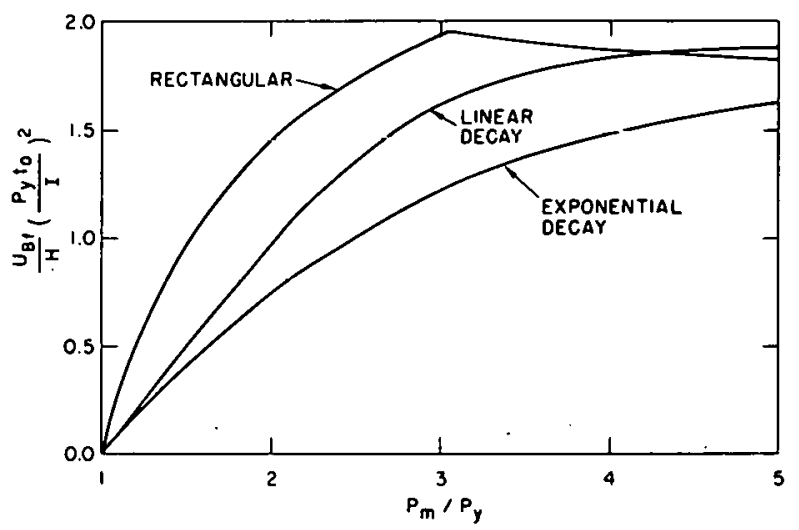

Fig. 20. $\left(\mathrm{U}_{\mathrm{Bf}} / \mathrm{H}\right)\left(\mathrm{P}_{\mathrm{y}_{0}} / \mathrm{I}\right)^{2}$ as a Function of $\mathrm{P}_{\mathrm{m}} / \mathrm{P}_{\mathrm{y}}$ in Small-deformation Range for Several Pulse Shapes: $\alpha=0.056$. ANL Neg. No. 113-4250 Rev. 2.

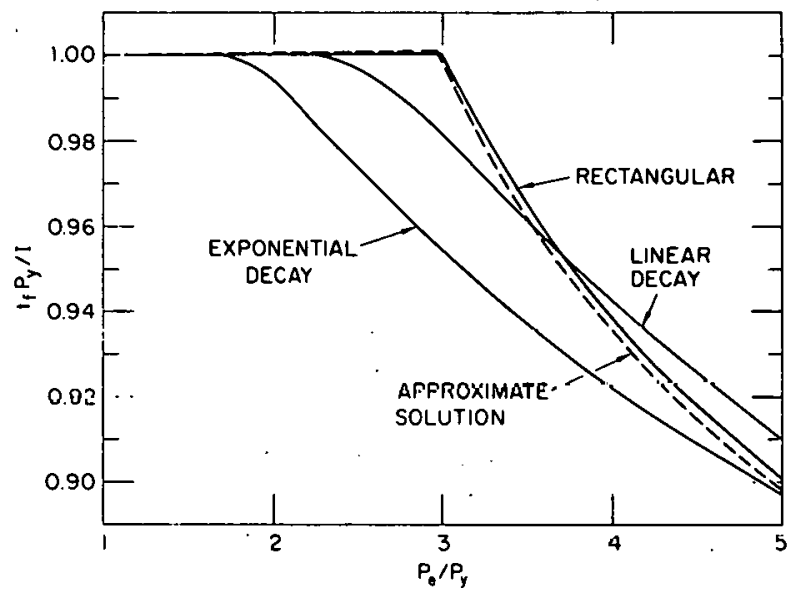

Fig. 22. $\mathrm{t}_{\mathrm{f}} \mathrm{P}_{\mathrm{y}} / \mathrm{I}$ as a Function of $\mathrm{P}_{\mathrm{e}} / \mathrm{P}_{\mathrm{y}}$ in Small-deformation Range for Several Pulse Shapes: $\alpha=0.03$. ANL Neg. No.. 113-4485 Rev. 2.

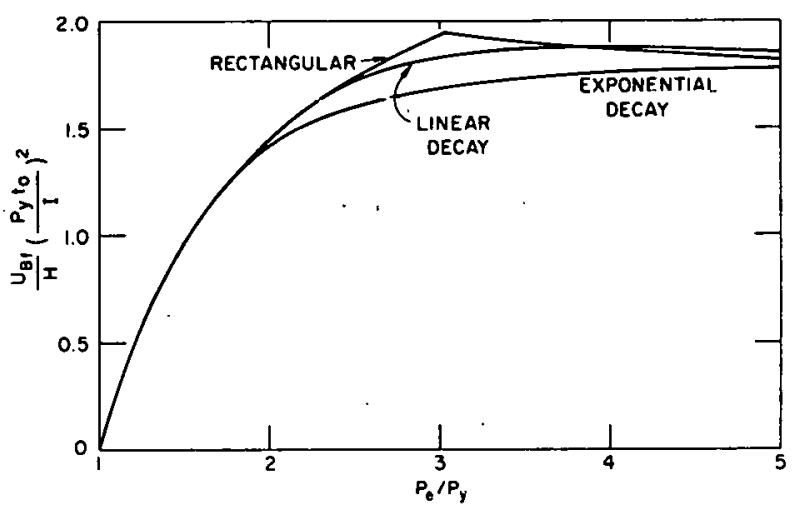

Fig. 21. $\left(\mathrm{U}_{\mathrm{Bf}} / \mathrm{H}\right)\left(\mathrm{P}_{\mathrm{y}} \mathrm{t}_{\mathrm{O}} / \mathrm{I}\right)^{2}$ as a Function of $\mathrm{P}_{\mathrm{e}} / \mathrm{P}_{\mathrm{y}}$ in Small-deformation Range for Several Pulse Shapes: $\alpha=0.056$. ANL Neg. No. 113-4251 Rev. 2.

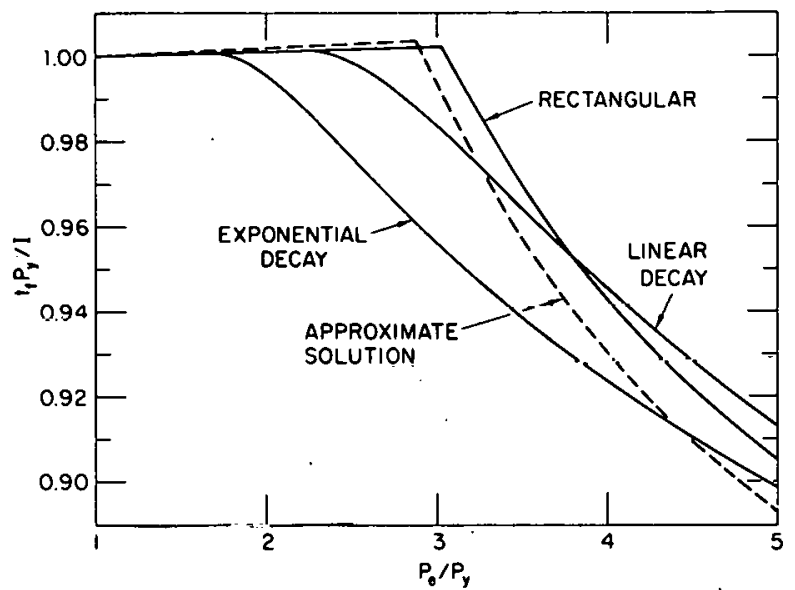

Fig. 23. $\mathrm{t}_{\mathrm{f}} \mathrm{P}_{\mathrm{y}} / \mathrm{I}$ as a Function of $\mathrm{P}_{\mathrm{e}} / \mathrm{P}_{\mathrm{y}}$ in Small-deformation Range for Several Pulse Shapes: $\alpha=0.056$. ANL Neg. No. 113-4566 Rev! 1.

As was shown in Sec. IV, the approximate solution for $\alpha \rightarrow 0$ is a good approximation to rectangular-pulse results for other values of $\alpha$, if $\mathrm{P}_{\mathrm{y}}$ is computed for the actual value of $\alpha$. The results of this section indicate that an arbitrarily shaped pulse can be replaced by an equivalent rectangular pulse given by Eqs. 20. Consequently, from Eqs. 9, 11 , and 25, we can compute the final plastic deformation in the small-deformation range from

$$
\left.\mathrm{U}_{\mathrm{Bf}} \approx 3 \mathrm{H}\left(\frac{\mathrm{I}}{\mathrm{P}_{\mathrm{y}} \mathrm{t}_{0}}\right)^{2}\left(1-\frac{\mathrm{P}_{\mathrm{y}}}{\mathrm{P}_{\mathrm{e}}}\right), \quad \mathrm{P}_{\mathrm{y}} \leq \mathrm{P}_{\mathrm{e}} \leq 3 \mathrm{P}_{\mathrm{y}} ;\right)
$$


and

$$
\left.\mathrm{U}_{\mathrm{Bf}} \approx \mathrm{H}\left(\frac{\mathrm{I}}{\mathrm{P}_{\mathrm{y}} \mathrm{t}_{0}}\right)^{2}\left(\frac{5}{3}+\frac{\mathrm{P}_{\mathrm{y}}}{\mathrm{P}_{\mathrm{e}}}\right), \quad \mathrm{P}_{\mathrm{e}}>3 \mathrm{P}_{\mathrm{y}},\right\}
$$

where $I$ and $P_{e}$ are computed from Eqs. 20.

We need a value for $t_{f}$ in order to perform the integrations in Eqs. 20. Based on Figs. 16, 22, and 23 and Eqs. 9 and 11 , we can determine $t_{f}$ from

$$
\mathrm{t}_{\mathrm{f}} \mathrm{P}_{\mathrm{y}} \approx \mathrm{I}, \quad \mathrm{P}_{\mathrm{y}} \leq \mathrm{P}_{\mathrm{e}} \leq 3 \mathrm{P}_{\mathrm{y}}
$$

and

$$
\left.t_{f} P_{y} \approx \frac{3}{4} I\left(1+\frac{P_{y}}{P_{e}}\right), \quad P_{e}>3 P_{y} .\right\}
$$

- Since $\mathrm{I}$ and $\mathrm{Pe}$ both depend on $t_{f}$, a transcendental equation is obtained for $t_{f}$ from Eqs. 27. However, as suming a value for $t_{f}$ to compute $I$ and $P_{e}$, computing a new value of $t_{f}$ from Eqs. 27 , substituting this result into Eqs. 20 to reevaluate $\mathrm{I}$ and $\mathrm{P}_{\mathrm{e}}$, etc., provide a quickly convergent procedure for determining $t_{f}$.

\section{LARGE-DEFORMATION RESPONSE TO STEP PULSES}

As was indicated in Sec. III, the hexagon deforms into a shape that can statically withstand a pressure higher than the initial yield load. Applying a step pulse results in a large-deformation dynamic plastic response which stops at some time $t_{f}$ dependent on the pulse height and the geometric parameter $\alpha$. Consequently, the response to a rectangular pulse with duration greater than $t_{f}$ is identical to the response to a step pulse with the same height. Results will be shown in this section for the final plastic deformations and response times. produced by step pulses.

Consider a step pulse (see Fig. 5b) defined by

$$
\left.\begin{array}{ll}
P(t)=P_{m}, & 0 \leq t<\infty ; \\
P(t)=0, & t<0 .
\end{array}\right\}
$$

Figure 24 shows the final plastic deformation at the midpoint of a side divided by the wall thickness as a function of the ratio of step-pulse height to limit load for various values of $\alpha$. The curves indicate that a thin hexagon must deform relatively more than a thick one in order to contain a given multiple of its respective yield load. This is demonstrated again in Fig. 25, where $U_{B f} / H$ is plotted as a function of $\alpha$ for $P_{m} / P_{y}=1.5,1.75$, and 2 . 


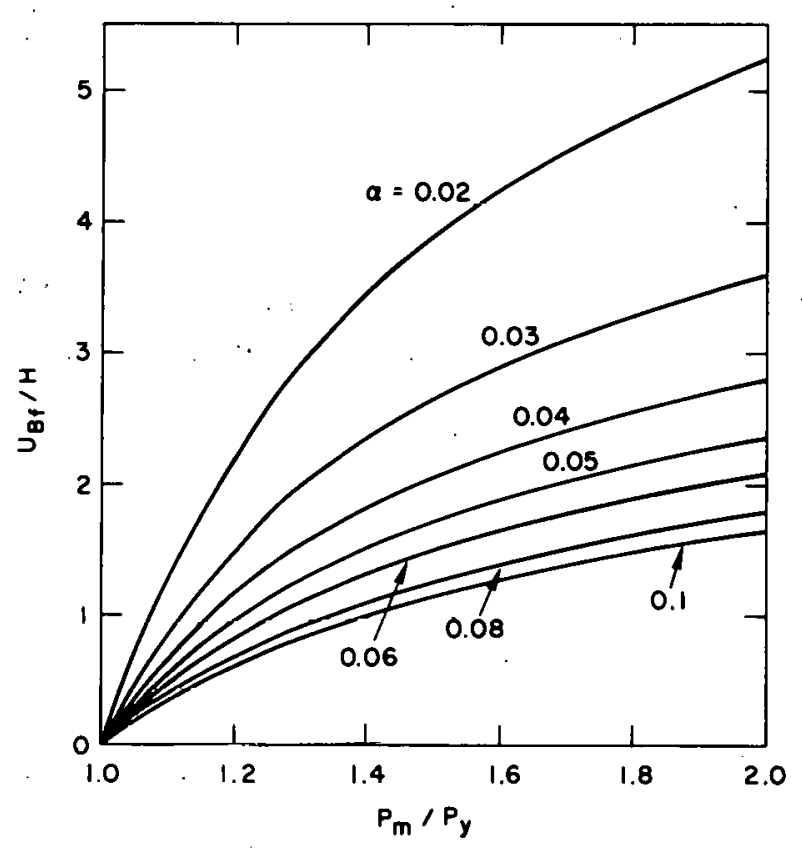

Fig. 24. Final Midside Deflection in Largedeformation Range as a Function of Step-pulse Height for Various $\alpha$. ANL Neg. No. 113-4227 Rev. 1.

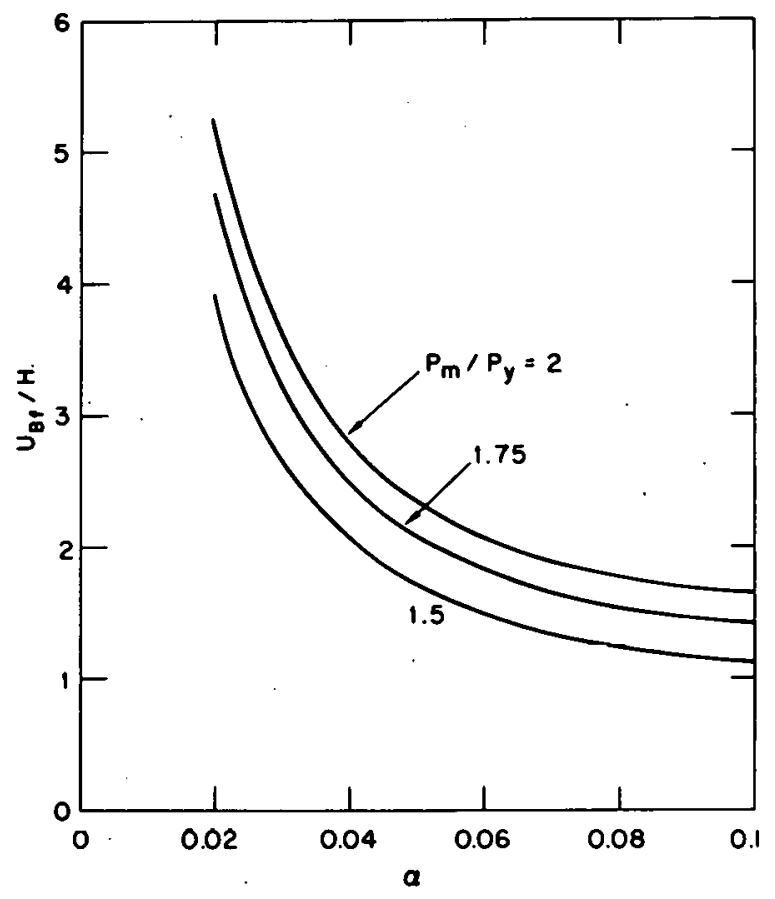

Fig. 25. Final Midside Deflection in Largedeformation Range as a Function of $\alpha$ for Various Values of $\mathrm{P}_{\mathrm{m}} / \mathrm{P}_{\mathrm{y}}$. ANL Neg. No. 113-4572.

Values of $\mathrm{P}_{\mathrm{m}}$ for step pulses exceeding $2 \mathrm{P}_{\mathrm{y}}$ produce, in general, deformations that are beyond the scope of this study and fall into category 4 described in Sec. I.

Figure 26 shows the final displacement of a corner divided by the wall thickness as a function of $\mathrm{P}_{\mathrm{m}} / \mathrm{P}_{\mathrm{y}}$ for various values of $\alpha$. Except for thick walls and small step-pulse height to yield load ratios, $U_{A f}$ is negative; i.e., the corners of the hexagon move inward in response to the step pulse.

Figure 27 is a plot of the ratio of response time $t_{f}$ to time constant $t_{0}$ as a function of step-pulse height divided by limit load for various values of $\alpha{ }^{*}$ As previously discussed, a rectangular pulse with duration greater than $t_{f}$ produces the same response as a step pulse of the same height.

*See Fig. 4 for $t_{0}$ values typical of the FFTF and EBR-II subassembly ducts. 


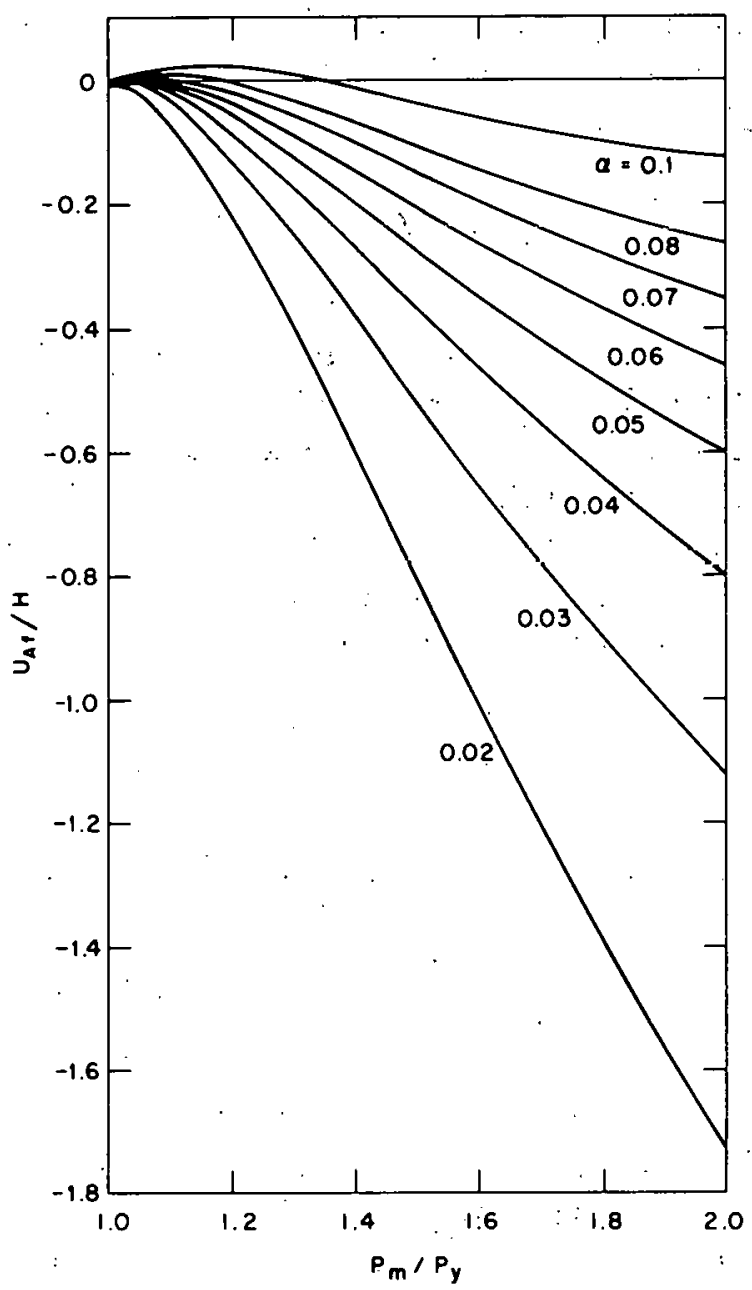

Fig. 26. Final Corner Deflection in Largedeformation Range as a Function of Step-pulse Height for Various $\alpha$. ANL Neg. No. 113-4480 Rev. 1.

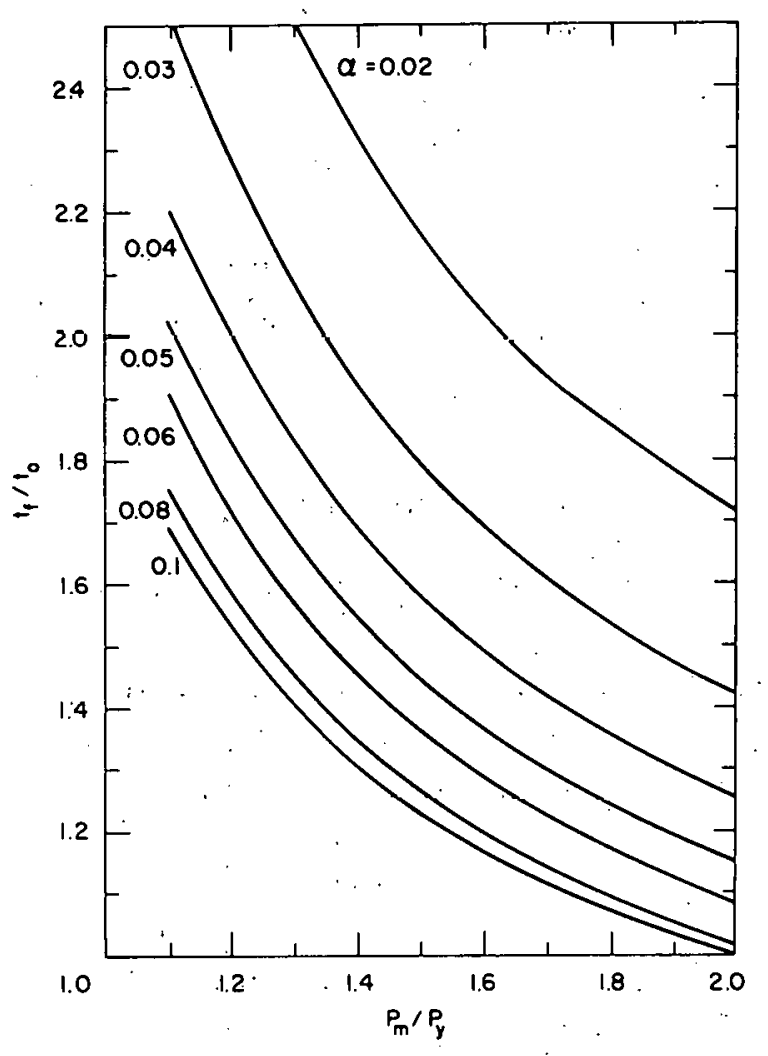

Fig. 27. Response Time in Large-deformation Range as a Function of Step-pulse Height for Various $\alpha$. ANL Neg. No. 113-4478.

\section{EFFECT OF PULSE SHAPE ON LARGE-DEFORMATION RESPONSE}

Parameter studies were performed to determine the effect of pulse shape on the large-deformation response of the hexagon. Some typical results are presented in this section, and an effort is made to relate the permanent plastic deformation produced by an arbitrary pulse to that produced by an equivalent step pulse.

Figure 28 shows results for an exponential-decay pulse, defined by Eq. 23 and depicted in Fig. 5c, with. $\alpha=0.056$. Computations were made for various combinations of the pulse parameters $P_{m}$ and. $t_{1}$. The peak pressures chosen were $\mathrm{P}_{\mathrm{m}}=0.26 \mathrm{P}_{0}, 0.3 \mathrm{P}_{0}, 0.35 \mathrm{P}_{0}, 0.4 \mathrm{P}_{0}, 0.45 \mathrm{P}_{0}, 0.5 \mathrm{P}_{0}$, and $0.55 \mathrm{P}_{0}$; for each of these values of $P_{m}$, calculations were performed for $t_{1}=t_{0}, 2 t_{0}, 3 t_{0}$, 
$4 t_{0}$, and $5 t_{0}$. The characteristic time constant $t_{0}$ for the plastic response is defined by Eq. 4 , and $P_{0}$ is the limit load of the circumscribed circular ring,

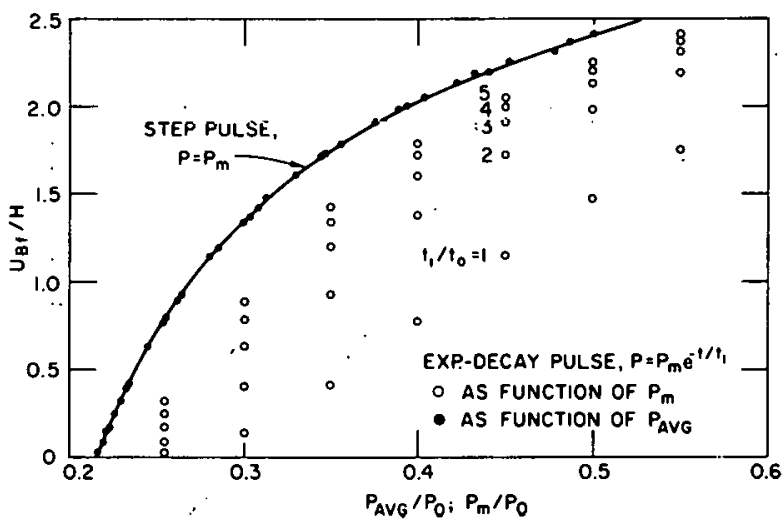

Fig. 28. Comparison of Results in Large-deformation Range for Exponential-decay and Step Pulses: $\alpha=0.056$. ANL Neg. No. 113-4235 Rev. 2. given by

$P_{0}=\sigma_{y} \frac{H}{L}$

The open circles on Fig. 28 are the values of $U_{B f} / H$ plotted as a function of $\mathrm{P}_{\mathrm{m}} / \mathrm{P}_{0}$, and the solid circles are the same values of $U_{B f} / H$ plotted as a function of $P_{A V G} / P_{0}$, where $P_{A V G}$ is the average pressure applied during the plastic response; i.e..

$$
P_{A V G}=\frac{1}{t_{f}} \int_{0}^{t_{f}} P(t) d t
$$

The curve is the permanent deforma-

tion produced by a step pulse of height $\mathrm{P}_{\mathrm{m}}$. It is apparent that a step pulse and an exponential-decay pulse having the same average value during the response produce essentially the same permanent plastic deformation.

Similar results are shown in Fig. 29 for linear-decay pulses (see Eq. 24 and Fig. 5d) with $\alpha=0.056$ and in Fig. 30 for exponential-decay pulses with $\alpha=0.03$. Again, the permanent plastic deformation is a function of the average pressure applied during the deformation, and the functional relationship is known from the step-pulse results.

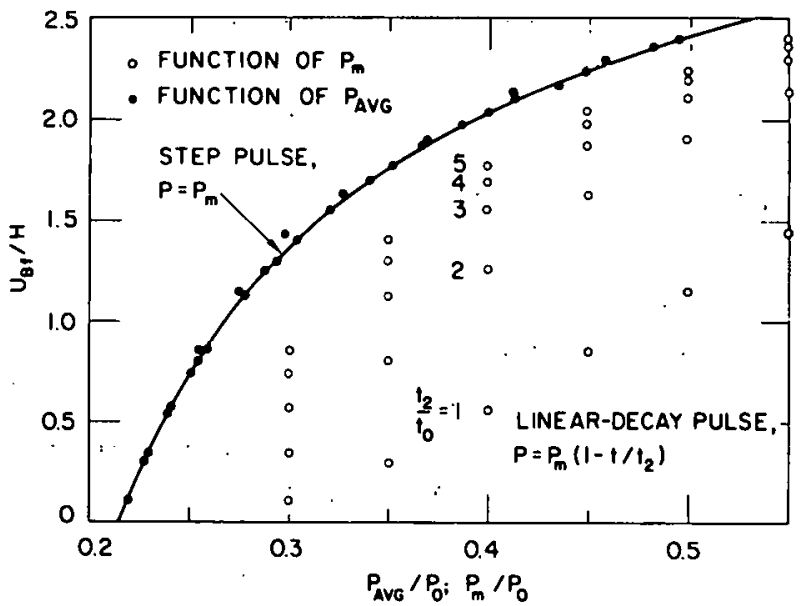

Fig: 29. Comparison of Results in Large-deformation Range for Linear-decay and Step Pulses: $\alpha=0.056$. ANL Neg. No. 113-4479 Rev. 1 .

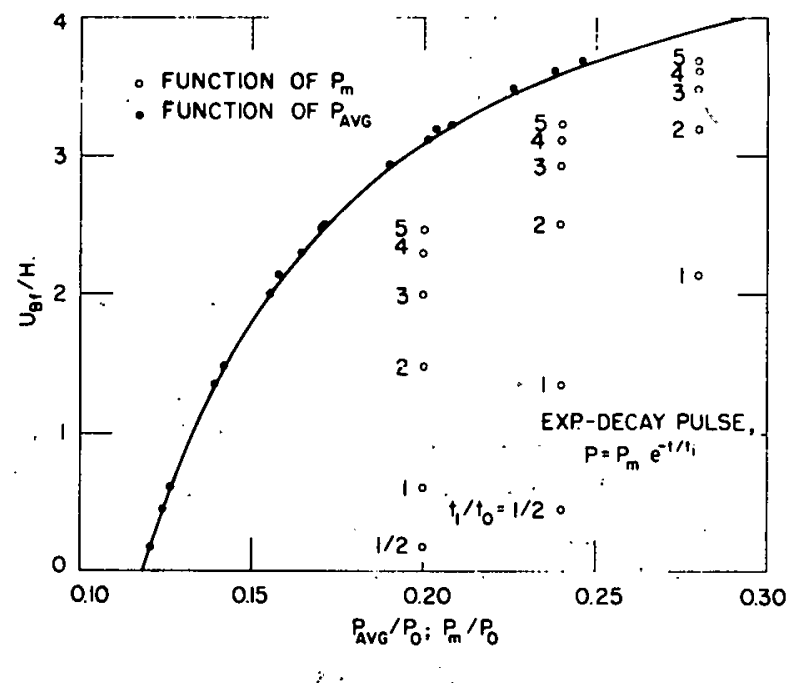

Fig. 30. Comparison of Results in Large-deformation Range for Exponential-decay and Step Pulses: $\alpha=0.03$. ANL Neg. No. 113-4568 Rev. 1 . 
In order to predict $\mathrm{U}_{\mathrm{Bf}}$ for a given arbitrary pulse without resorting to DYPLHX, it is necessary to estimate $t_{f}$. Then, the average pressure can be computed from Eq. 30, and Fig. 24 can be used to find the corresponding value of $U_{B f}$. We will next consider some possible procedures for estimating $t_{f}$.

Figure 31 gives $t_{f} / t_{0}$ for the exponential-decay pulse with $\alpha=0.056$ as a function of the pulse time constant $t_{1} / t_{0}$ for various values of $P_{m} / P_{0}$. The

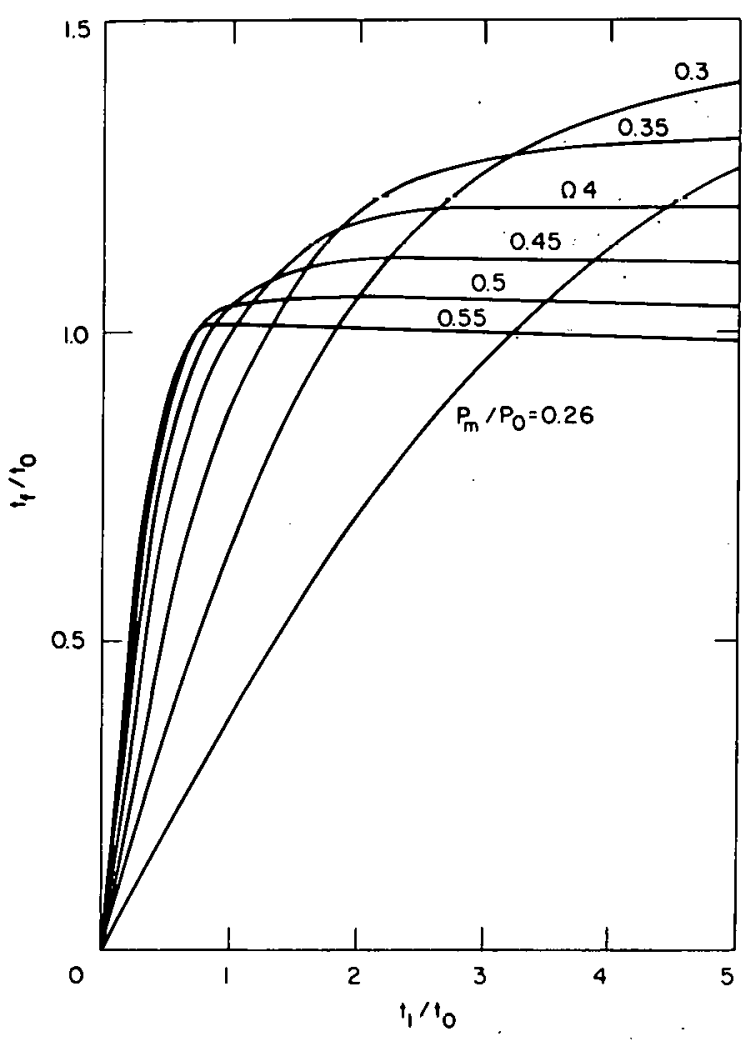

Fig. 31. Response Duration for Exponentialdecay Pulse as a Function of Pulse Time Constant for Various Values of Peak Pressure: $\alpha=0.056$. ANL Neg. No. 113-4569 Rev. 1. initial linear portion of each curve corresponds to the small-deformation range (see Eqs. 20 and 27) where the duration of response is proportional to the time constant of the pulse. For longerduration pulses, the shape of the curve depends strongly on the value of $P_{m} / P_{0}$. As $t_{1} / t_{0} \rightarrow \infty$, each curve asymptotically approaches the response duration for a step pulse of height $P_{m}$, given by Fig. 27 . The combination of the initial linear portion, computed from Eqs. 27, and the asymptote at infinity can be used to predict response durations. However, if the prediction exceeds the actual value of $t_{f}$, the average pressure computed from Eq. 30 will be underestimated; $*$ this will, in turn, lead to an underestimation of $U_{B f}$ and, consequently, a nonconservative result.

Similar results are shown in Fig. 32 for a linear-decay pulse with $\alpha=0.056$ and in Fig. 33 for an exponential decay pulse with $\alpha=0.03$.

In the small-deformation range, $t_{f} P_{y} / I \approx 1$, as can be seen from Eqs. 27 and Figs. 22 and 23; this approximation can then be used to estimate $t_{f}$ for a given pulse. We will investigate next to see whether a similar approximation is valid for the large-deformation range. Figure 34 shows the impulse I applied during plastic deformation for the exponential decay pulse with $\alpha=0.056$; the nondimensional quantity $I / \mathrm{P}_{\mathrm{y}} \mathrm{t}_{0}$ is plotted as a function of $t_{1} / t_{0}$ for various values of $P_{m} / P_{0}$. The initial straight line portion of each curve corresponds to the small-deformation solution, and step-pulse results are approached asymptotically as $t_{1} / t_{0} \rightarrow \infty$. Combining these results with those of Fig. 31, we can then plot $t_{f} \mathrm{P}_{\mathrm{y}} / \mathrm{I}$, as shown in Fig. 35. We see that $t_{f} P_{y} / I$ deviates strongly from unity as $P_{m} / P_{0}$ and $t_{1} / t_{0}$ increase.

\footnotetext{
$*_{\text {It }}$ is assumed that the applied pressure eventually decreases with time.
} 


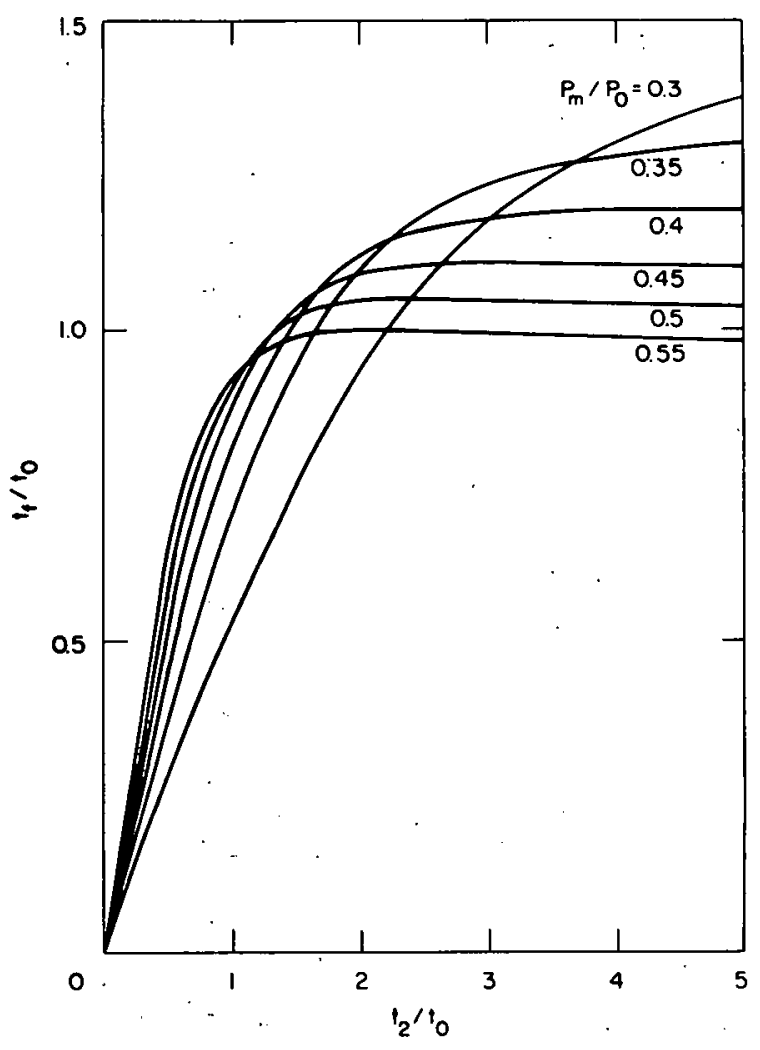

Fig. 32. Response Duration for Linear-decay Pulse as a Function of Pulse Duration for Various Values of Peak Pressure: $\alpha=0.056$. ANL Neg. No. 113-4570 Rev. 1.

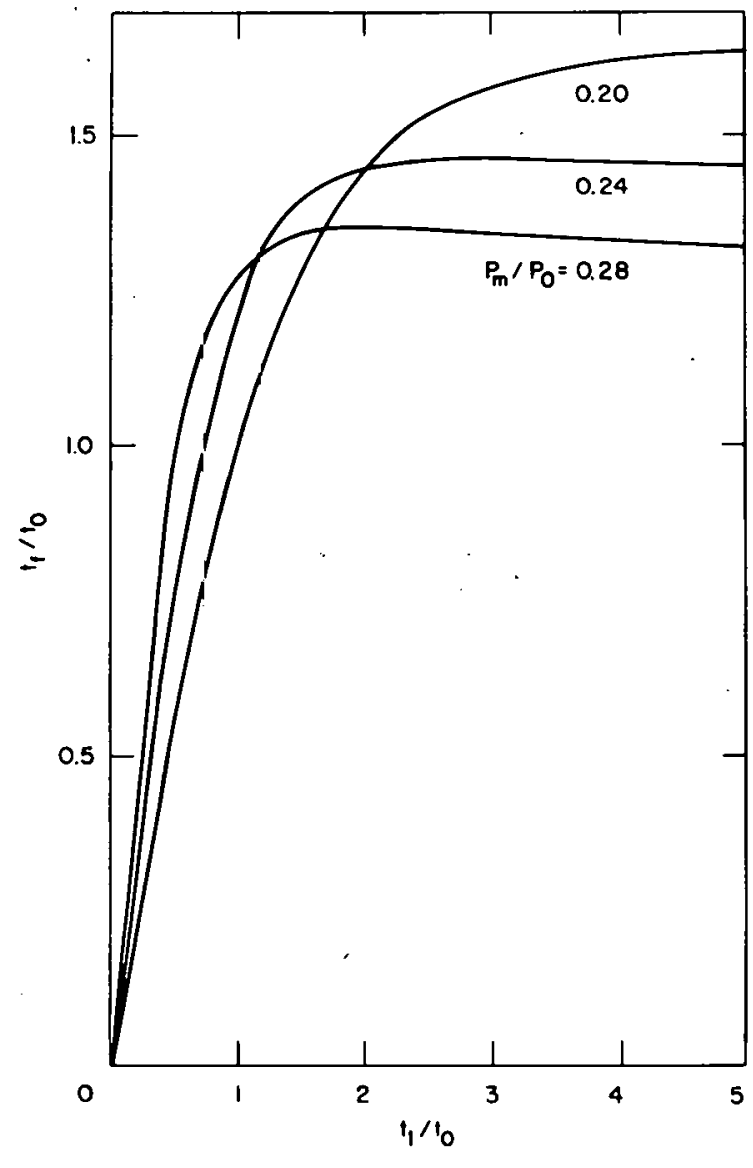

Fig. 33. Response Duration for Exponential-decay Pulse as a Function of Pulse Time Constant for Various Values of Peak Pressure: $\alpha=0.03$. ANL Neg. No. 113-4563 Rev. 1 .

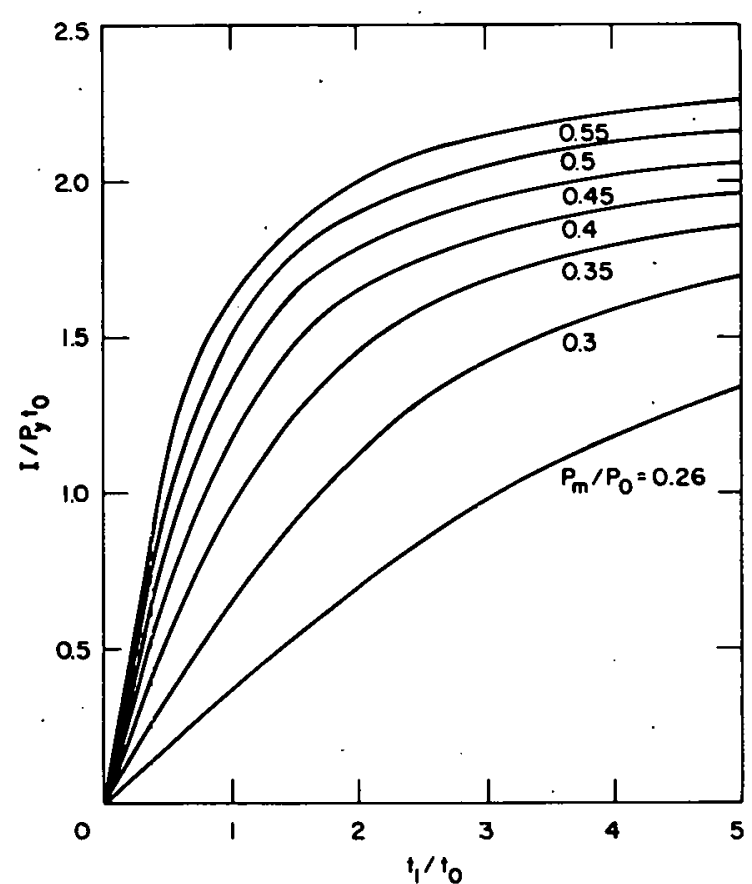

Fig. 34. Applied Impulse during Deformation Produced by an Exponentialdecay Pulse: $\alpha=0.056$. ANL Neg. No. 113-4555 Rev. 1. 


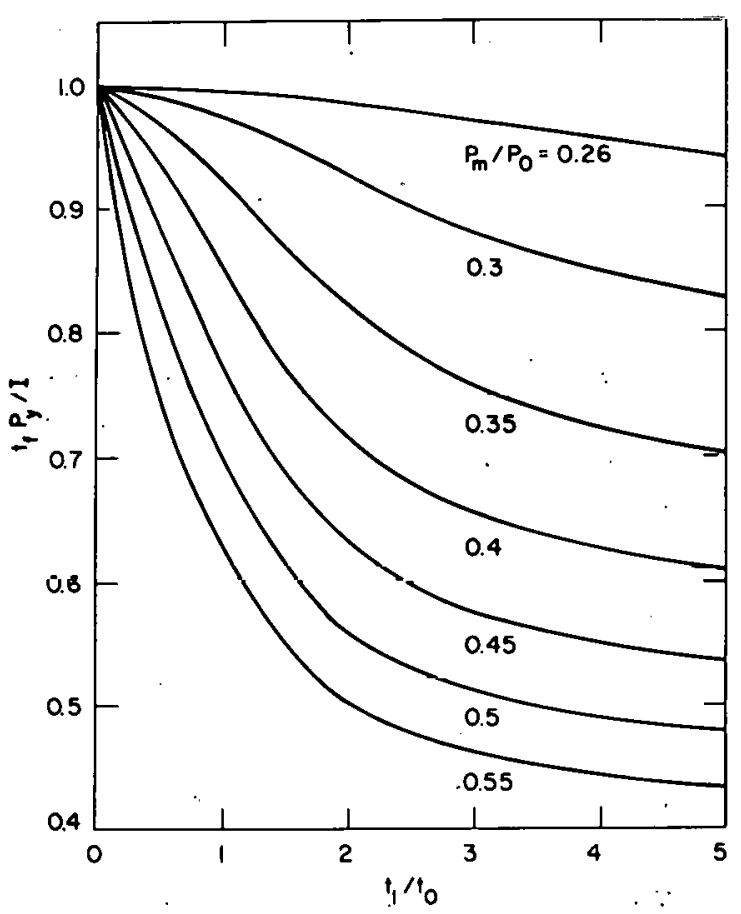

Fig. 35

$\mathrm{t}_{\mathrm{f}} \mathrm{P}_{\mathrm{y}} / \mathrm{I}$ in Large-deformation Range for an Exponential-decay Pulse: $\alpha=0.056$. ANL Neg. No. 113-4557 Rev. 1.

Consequently, the simple approximation valid in the small-deformation range is not useful in the large-deformation range. Moreover, the use of this approximation would lead to an overestimation of $t_{f}$ and a corresponding nonconservative underestimation of $P_{A V G}$ and $U_{B f}$.

In experiments in which $U_{B}(t), P(t), U_{B f}$, and $t_{f}$ can be measured, $P_{A V G}$ is easily determined from $P$ and $t_{f}$, and the correlation of $U_{B f}$ to $P_{A V G}$ can be investigated. For analytical studies, however, there appears to be no simple relationship analogous to Eqs. 27 for the small-deformation range to predict $t_{f}$ for the large-deformation response. Without an a priori determination of $t_{f}$ for a given pulse, either (1) the response to. the step pulse with the same height as the peak (rather than the average) pressure of the pulse may be used to bound the permanent deformation; or (2) the program DYPLHX may be used to solve the deformation problem.

\section{DYNAMIC LOAD FACTOR FOR PLASTIC DEFORMATION}

The deformation produced by a dynamically applied pressure may exceed that produced by the same load applied statically because of the kinetic energy possessedby the deforming hexagon. In this section, the dynamic effect of an initial instantaneous jump is calculated by comparing the permanent plastic deformation caused by a step pulse with the deformation produced by a static load of the same magnitude. The ratio of the respective midside deformations will be called the dynamic load factor D. Step-pulse results were discussed in Sec. VI, and a static-deformation analysis was included in Ref. 1; appropriate portions of the static analysis are repeated here for convenience. 
As shown in Ref. 1 , a static load $P_{S}$ produces an angular deformation $\theta$ of a half-side of the hexagon given by

$$
\begin{gathered}
\left(8 \alpha^{2} \sigma_{y}^{2}+2 \sigma_{y} P_{s}-P_{s}^{2}\right) \tan ^{2} \theta+2 \sqrt{3} P_{s}\left(2 \sigma_{y}-P_{s}\right) \tan \theta+ \\
8 \alpha^{2} \sigma_{y}^{2}-2 \sigma_{y} P_{s}-6 P_{s}^{2}=0 .
\end{gathered}
$$

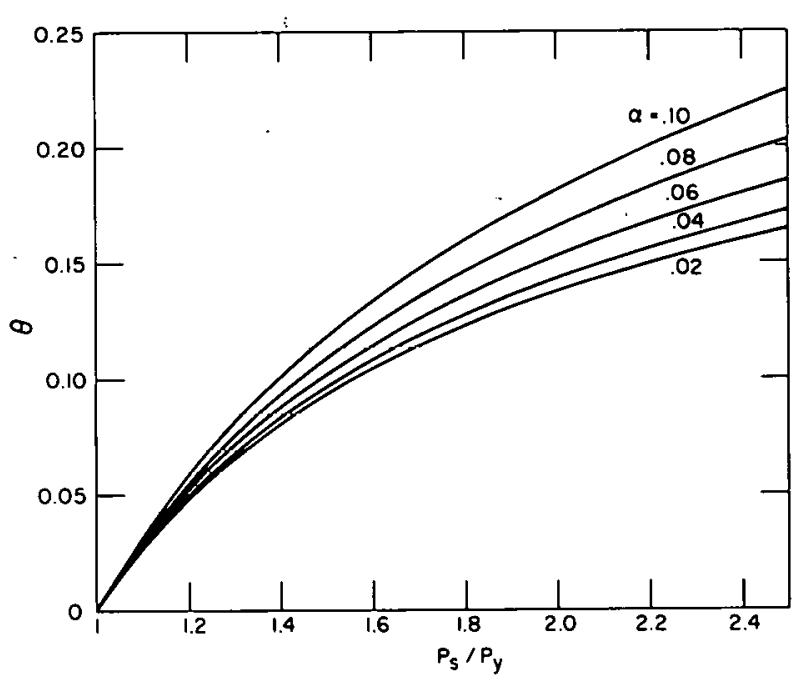

Fig. 36. Angular Deflection of Half-side of Hexagon Produced by Static Load. ANL Neg. No. 113-4241 Rev. 1.
The relationship between $\theta$ and $P_{s} / P_{y}$ is shown in Fig. 36. The corner.and midside static deflections are found from

$$
\left.\begin{array}{l}
\mathrm{U}_{\mathrm{A}}=\Delta_{\mathrm{T}} \cos \theta-\mathrm{L}(1-\cos \theta), \\
\text { and } \\
\mathrm{U}_{\mathrm{B}}=\frac{1}{2} \sqrt{3} \mathrm{U}_{\mathrm{A}}+\frac{1}{2}\left(\mathrm{~L}+\Delta_{\mathrm{T}}\right) \sin \theta,
\end{array}\right\}
$$

where $\Delta_{\mathrm{T}}$ is the total extensional strain in a side. The differential equation

$$
\frac{\mathrm{d} \Delta_{\mathrm{T}}}{\mathrm{d} \theta}=\frac{\mathrm{P}_{\mathrm{s}} \mathrm{L}}{2 \sigma_{\mathrm{y}}}(2 \sqrt{3} \cos \theta+\sin \theta),
$$

can be easily integrated numerically

for $\Delta_{T}$, using Eq. 31. The result is then substituted into Eq. 32 to compute $\mathrm{U}_{\mathrm{B}} / \mathrm{H}$ and $\mathrm{U}_{\mathrm{A}} / \mathrm{H}$, which are shown in Figs. 37 and 38 , respectively, as functions of $\mathrm{P}_{\mathrm{s}} / \mathrm{P}_{\mathrm{y}}$. These figures should be compared to the corresponding curves (Figs. 24 and 26) for the step pulse.

The dynamic-load factor $D$, defined as the ratio of $U_{B f}$ produced by a step pulse (Fig. 24) to $U_{B}$ produced by a static load (Fig. 37), is shown in Fig. 39 as a function of $P_{m} / P_{y}$ for various values of $\alpha$; here, $P_{m}$ represents the step-pulse height or the magnitude of the static load. We see that the dynamic-load factor varies between 2.0 and approximately 1.7 as $P_{m}$ varies between $\mathrm{P}_{\mathrm{y}}$ and $2 \mathrm{P}_{\mathrm{y}}$.

The limiting value of two at $P_{m}=P_{y}$ is particularly interesting in that the dynamic-load factor for an elastic one-degree-of-freedom system is also two. Since no elastic behavior is included in this hexagon-deformation analysis, it is intriguing that the two types of analyses match at the transition point. 


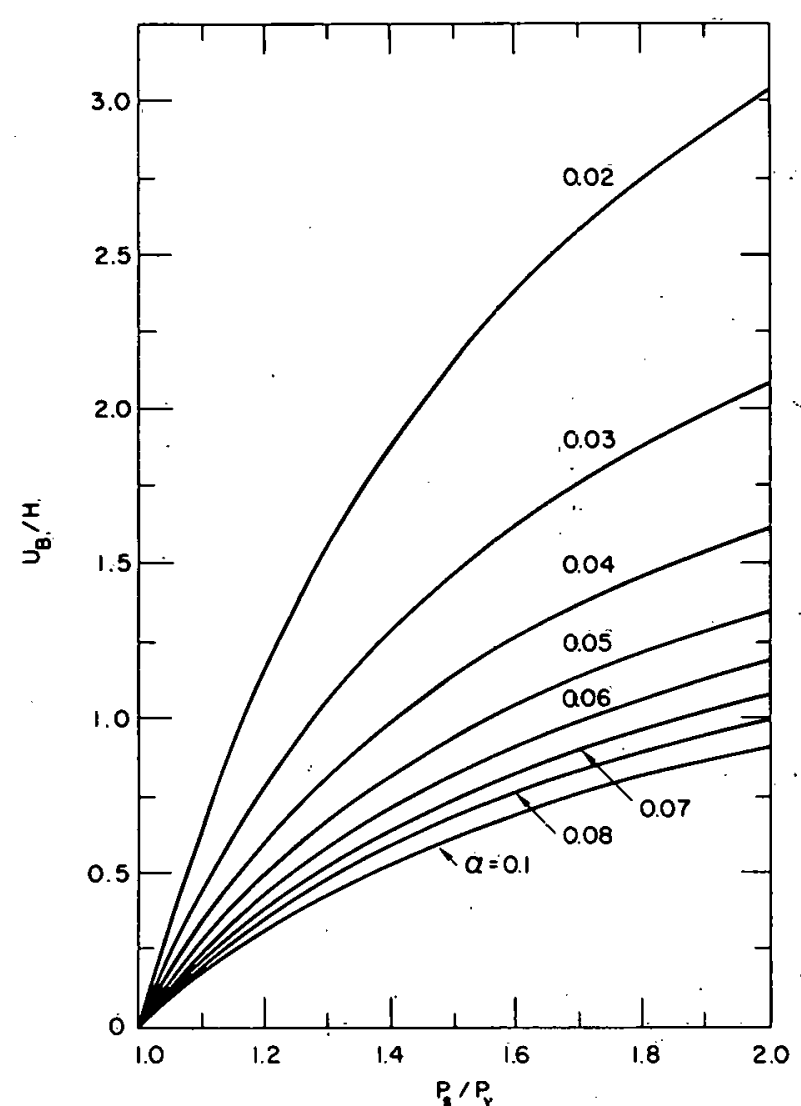

Fig. 37. Midside Deflection Produced by Static Load. ANL Neg. No. 113-4249 Rev. 1.

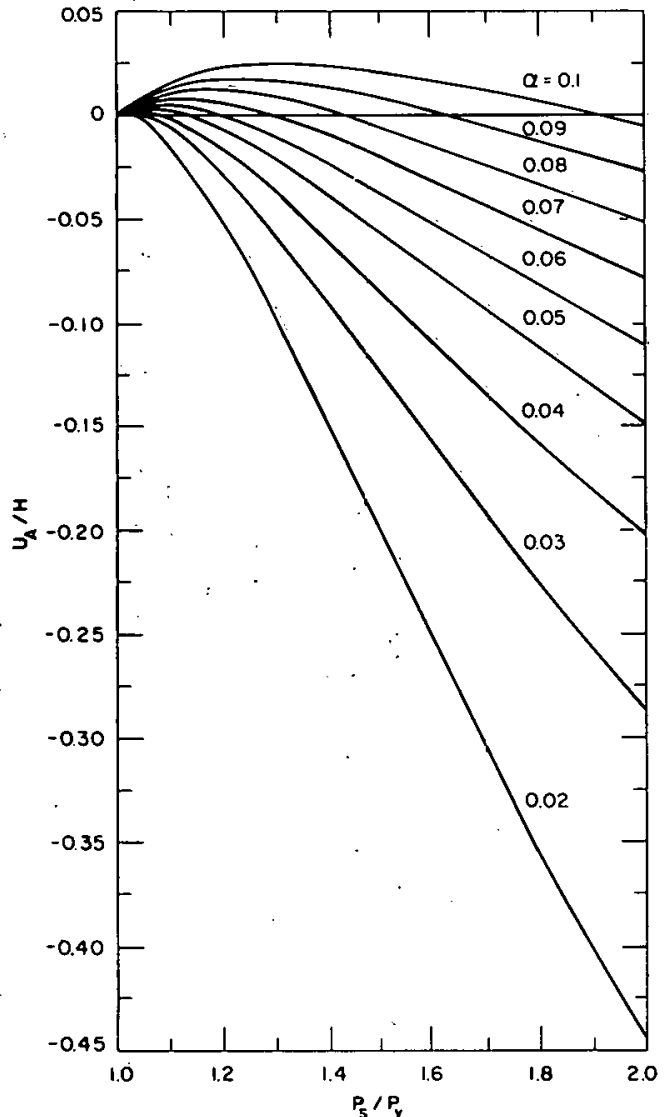

Fig. 38. Corner Deflection Produced by Static Load. ANL Neg. No. 113-4234.

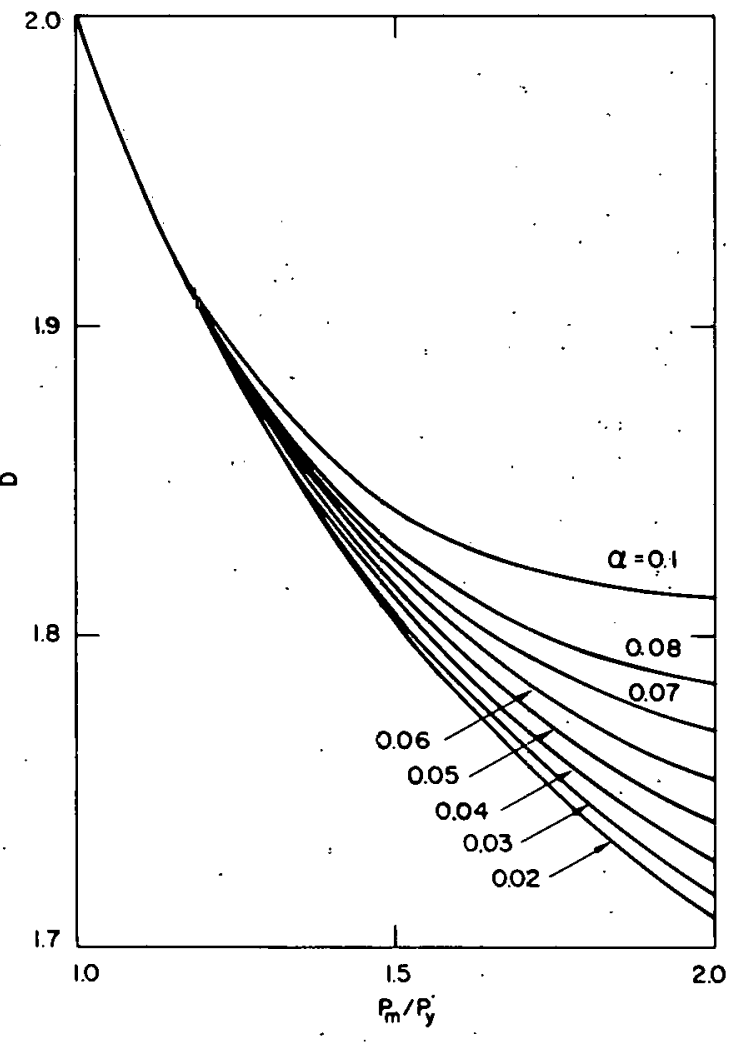

-Fig. 39: Dynamic-load Factor as a Function of $\mathrm{P}_{\mathrm{m}} / \mathrm{P}_{\mathrm{y}}$ for Various $\alpha$. ANL Neg. No. 113-4571. 
A procedure for estimating the plastic deformation of the hexagon produced by an arbitrary pulse was developed in Sec. V for the small-deformation range. For the large-deformation range, Secs. VI and VII give a procedure whereby the deformation produced by an arbitrary pulse is bounded by the deformation produced by a step pulse. Some simple example problems will be solved in this section to illustrate these procedures.

Problem 1. Consider an exponential-decay pulse $P=P_{m} \exp \left(-t / t_{1}\right)$. Let $\alpha=0.03$ for the hexagon and take $P_{m}=0.006 \sigma_{y}$ and $t_{1}=0.05 t_{0}$, where $t_{0}$ is computed from the material properties through Eq. 4. Estimate $\mathrm{U}_{\mathrm{Bf}} / \mathrm{H}$.

From Eq. 3,

$$
\dot{P}_{y}=\frac{8 \alpha^{2} \sigma_{y}}{1+\sqrt{1+48 \alpha^{2}}}=0.00356 \sigma_{y}
$$

so that

$$
\mathrm{P}_{\mathrm{m}} / \mathrm{P}_{\mathrm{y}}=1.68
$$

From Fig. 24, we have that an upper bound on the deformation produced by a pulse with this peak value for $\alpha=0.03$ is

$$
\left(\mathrm{U}_{\mathrm{Bf}} / \mathrm{H}\right)_{\text {step pulse }}=3.1
$$

This means that no matter how long the pulse acts, the deformation at the midside cannot exceed $3.1 \mathrm{H}$.

To estimate the deformation from the small-deformation correlation, it is necessary to determine $t_{f}$. From Eqs. 27, since $P_{m}<3 P_{y}$,

$$
t_{f} P_{y}=I=\int_{0}^{t_{f}} P(t) d t
$$

$\left(P_{e} \leq P_{m}\right.$, so if $P_{m}<3 P_{y}$, then $\left.P_{e}<3 P_{y} \cdot\right)$ Substituting for. $P(t)$ in $E q .37$ gives

$$
\frac{t_{f}}{t_{1}}=\frac{P_{m}}{P_{y}}\left[1-\exp \left(-t_{f} / t_{1}\right)\right]
$$

A trial-and-error solution then results in

$$
t_{f}=1.1524 t_{1} .
$$


Using this value of $t_{f}$ in Eqs. 20 and 21 gives

$$
\left.\begin{array}{rl}
q & =\exp \left(-t_{f} / t_{1}\right)=0.3159, \\
I & =P_{m} t_{1}(1-q)=0.0041050 y t_{1}, \\
t_{\text {mean }} & =t_{1}\left(1-\frac{t_{f}}{t_{1}} \frac{q}{1-q}\right)=0.4679 t_{1}, \\
t_{e} & =2 t_{\text {mean }}=0.9358 t_{1},
\end{array}\right\}
$$

and

$$
\begin{aligned}
\mathrm{P}_{\mathrm{e}} & =\mathrm{I} / \mathrm{t}_{\mathrm{e}}=0.004386 \sigma_{\mathrm{y}} \\
& =1.231 \mathrm{P}_{\mathrm{y}}
\end{aligned}
$$

Substitution of these values in Eqs. 26 results in

$$
\mathrm{U}_{\mathrm{Bf}} / \mathrm{H}=0.7487\left(\frac{\mathrm{t}_{1}}{\mathrm{t}_{0}}\right)^{2}
$$

For $t_{1}=0.05 t_{0}$, we arrive finally at

$$
\left(\mathrm{U}_{\mathrm{Bf}} / \mathrm{H}\right)_{\text {equiv. pulse }}=0.00187
$$

The DYPLHX computation gives

$$
\left(\mathrm{U}_{\mathrm{Bf}} / \mathrm{H}\right)_{\mathrm{DYPLHX}}=0.00185
$$

so the approximate correlation procedure for relating an arbitrary pulse to an equivalent rectangular pulse gives a very good result for this problem.

Problem 2. Consider the same pulse as Problem 1 , but let $t_{1}=0.5 t_{0}$.

The results given in Eqs. 34-41 hold. for this problem also. Substitution of the new value of $t_{1}$ into Eq. 41 gives

$$
\left(\mathrm{U}_{\mathrm{Bf}} / \mathrm{H}\right)_{\text {equiv. }} \text { pulse }=0.187
$$

and the computer calculation gives

$$
\left(\mathrm{U}_{\mathrm{Bf}} / \mathrm{H}\right)_{\mathrm{DYPLHX}}=0.175
$$

Here, the estimate is not as accurate as for Problem 1, but the equivalent pulse-correlation procedure overestimates the "exact" computer result by only about $7 \%$. 
Problem 3. Consider the same pulse as Problem 1, but let $t_{1}=t_{0}$.

Eq. 41 gives

Again, the results of Problem 1 hold through Eq. 41. For $t_{1}=t_{0}$,

$$
\left(\mathrm{U}_{\mathrm{Bf}} / \mathrm{H}\right)_{\text {equiv, pulse }}=0.749,
$$

and the computer result for the given pulse is

$$
\left(\mathrm{U}_{\mathrm{Bf}} / \mathrm{H}\right)_{\text {DYPLHX }}=0.598
$$

Here, the approximate procedure overestimates by $25 \%$ the hexagon deformation computed from DYPLHX.

Problem 4. Consider the same pulse as Problem 1 , but let $t_{1}=2 t_{0}$.

For this value of $t_{1}$, Eq. 41 gives

$$
\left(\mathrm{U}_{\mathrm{Bf}} / \mathrm{H}\right) \text { equiv. pulse }=3.0 \text {, }
$$

which is about the same as the upper bound for large deformation given by Eq. 36. The computer result is

$$
\left(\mathrm{U}_{\mathrm{Bf}} / \mathrm{H}\right)_{\text {DYPLHX }}=1.48,
$$

so that both the equivalent rectangular-pulse estimate for small-deformation and the large-deformation step-pulse bound overestimate the DYPLHX result by about $100 \%$. The "middle" region where the small-deformation estimate and the large-deformation bound give about the same result is the region in which they each overestimate the DYPLHX result by the greatest amount.

Problem 5. Consider the same pulse as Problem 1, but let $t_{1}=5 t_{0}$.

Substitution of $t_{1}=5 t_{0}$ into Eq. 40 gives

$$
\left(\mathrm{U}_{\mathrm{Bf}} / \mathrm{H}\right)_{\text {equiv. pulse }}=18.7,
$$

which exceeds the upper bound for large deformation

$$
\left(\mathrm{U}_{\mathrm{Bf}} / \mathrm{H}\right)_{\text {step pulse }}=3.1 .
$$

Consequently, $3.1 \mathrm{H}$ should be used as the estimate for $\mathrm{U}_{\mathrm{Bf}}$. The computer calculation gives

$$
\left(\dot{U}_{B f} / H\right)_{D Y P L H X}=2.47,
$$

so the error in using Eq. 51 as the estimate is about $25 \%$. 
Figure 40 shows $\mathrm{U}_{\mathrm{Bf}} / \mathrm{H}$ for the pressure pulse of these problems, i.e., an exponential-decay pulse with $\mathrm{P}_{\mathrm{m}}=0.006 \sigma_{\mathrm{y}}$ and $\alpha=0.03$, plotted as a func-

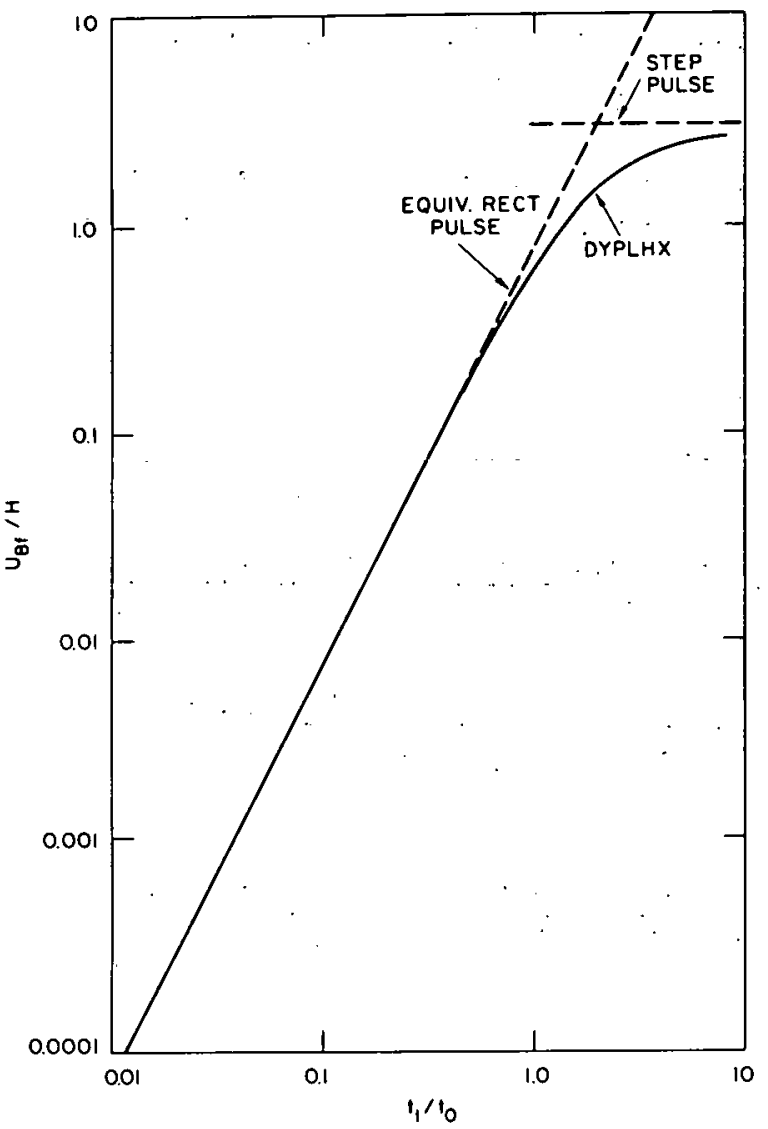

Fig. 40. Comparison of Results and Bounds for Exa mple Problems: $\alpha=0.03, P_{m}=0.006 \sigma_{y}$. ANL Neg. No. 113-4559 Rev. 1. tion of $t_{1} / t_{0}$ on a log-log scale. The solid line is the DYPLHX result, the inclined dashed line is the equivalent rectangular-pulse solution for small deformation, and the horizontal dashed line is the upper bound from the largedeformation, step-pulse analysis. Since each approximation provides an upper bound to the solution, whichever is smaller should be taken as the more accurate estimate. The greatest deviation between the least upper bound and the solution occurs where the two approximations intersect.

\section{SUMMARY AND CONCLUSIONS}

In Secs. V and VII, the effect of pulse shape on the permanent plastic deformation of a hexagon was shown to be quite significant. Correlation procedures for relating permanent deformation to simple parameters associated with the pulse shape are developed in Secs. IV and $V$ for the small-deformation range and Secs. VI and VII for the largedeformation range; sample calculations using these procedures are made in Sec. IX. Characteristic response times are related to pulse durations and hexagon parameters in Secs. IV and VI. A dynamic-load-factor analysis is given in Sec. VIII to indicate the relative magnitude of dynamic and static deformation for a given peak pressure. All results are presented for a range of values of hexagon dimensions typical of physically realistic reactór-subassembly designs.

The procedure for correlating permanent plastic deformation to pulse parameters in the small-deformation range implies that an earlier occurring peak produces more deformation than a later one of the same height and impulse. This is because an earlier peak results in a smaller value of the

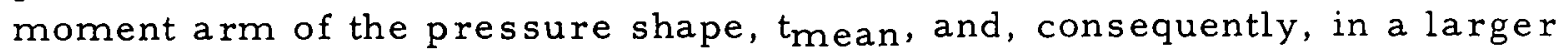
value of the effective pressure, Pe. (See Eqs. 20 and 21.) The characteristic response time in the small-deformation range is proportional to the time scale of the pulse and is independent of the material and geometric constants of the hexagon, except for the limit load, $P_{y}$. 
In the large-deformation range, the permanent plastic deformation depends on the average pressure applied during the deformation and therefore is not sensitive to the location of the peak pressure. The characteristic response time is virtually independent of the pulse time-scale for longduration pulses (see Figs. 27, 31,32, and 33), but depends on the material and geometric constants of the hexagon through $\alpha, t_{0}$, and $\mathrm{P}_{\mathrm{y}}$.

The dynamic-load-factor analysis shows that the effect of suddenly applying a pressure $\mathrm{P}_{\mathrm{m}}$ is to multiply the deformation produced by the same load applied statically by a factor between 2.0 and 1.7 for $\mathrm{P}_{\mathrm{m}}$ in the range $\mathrm{P}_{\mathrm{y}}$ to $2 \mathrm{P}_{\mathrm{y}}$.

\section{REFEREN CES}

1. C. K. Youngdahl, Large-deformation Plastic Response of Hexagons to Pressure Pulses, AN L-7985 (Mar 1973).

2. C. K. Youngdahl, Correlation Parameters for Eliminating the Effect of Pulse Shape on Dynamic Plastic Deformation, J. Appl. Mech. 37(3), 744-752(Sept 1970).

3. C. K. Youngdahl, Dynamic Plastic Deformation of Circular Cylindrical Shells, J. Appl. Mech. 39E(3), 746-750 (Sept 1972). 